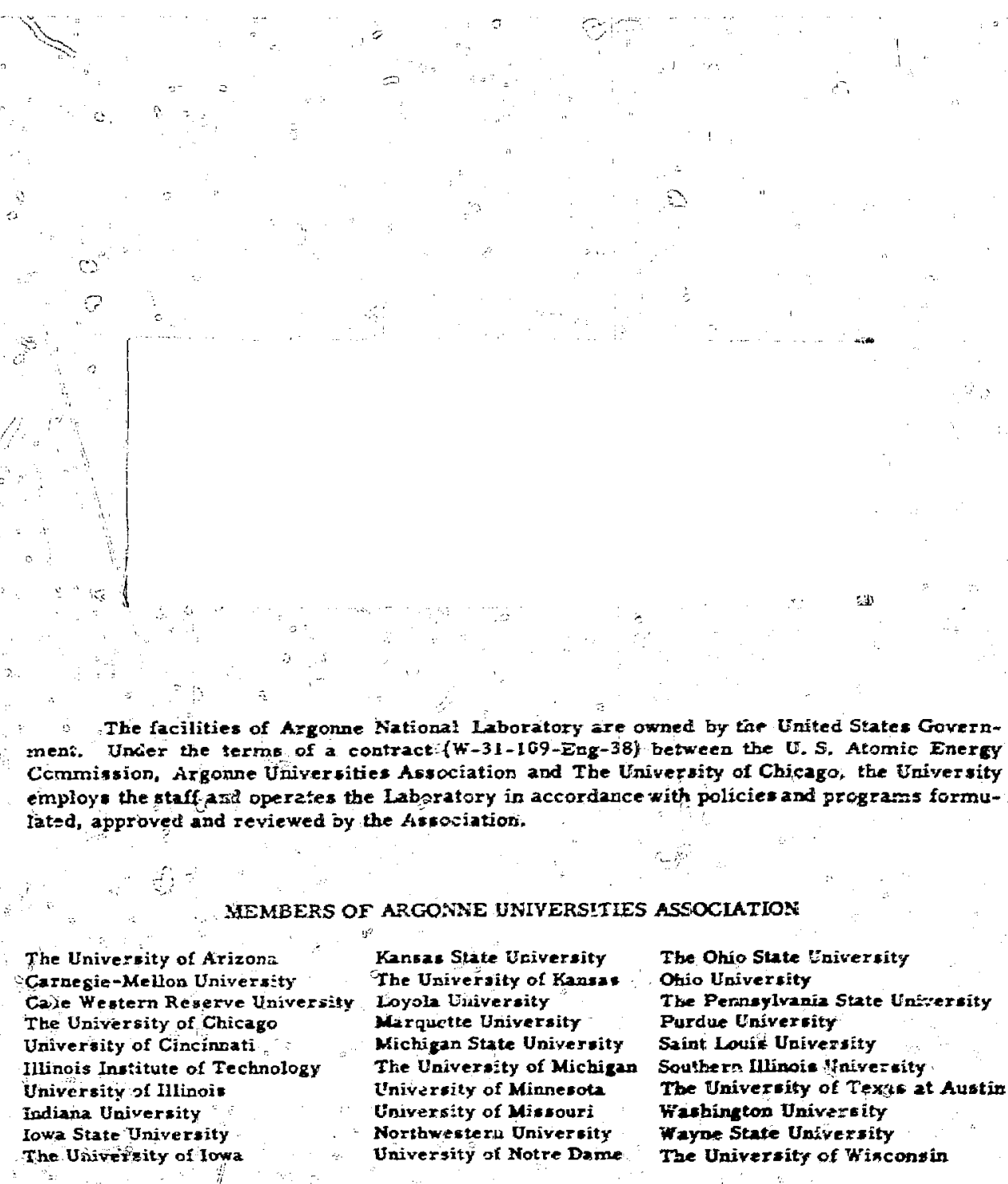




\section{ANL./NDM-13 \\ RESPONSE OF SEVERAL THRESHOLD \\ REACTIONS IN REFERENCE FISSION \\ NEUTRON FIELDS}

by

Donaid 2. Smith and James W. Meadows

June 1975

In January 1975, the research and development functions of the former U.S. Atomfc Energy Comnission were incorporated into those of the U.S. Bnergy Riesearch and Development Administration.

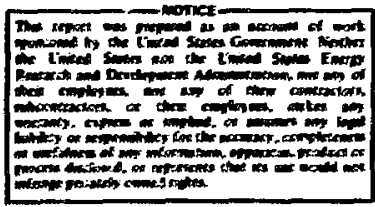

Applied Physics Diviston

Argonme National Laboratory

9700 South Cass Avenue

Argonne, Illinots 60439

U.S.A. 
NUCL.EAR DATA AND MEASUREMENTS SERIES

The Nuclear Data and Measurements Series presents results of studies in the field of microscopıc nuclear data. The primary objective is the dissemination of information in the comprehensive form required for nuclear technology applications. This series is devoted to: a) Measured microscoplc nuclear parameters, b) Experimental techniques and facilities employed in data measurements, c) The analysis, correlation and interpretation of nuclear data, and d) The evaluation of nuclear data. Contributions to this Series are reviewed to assure technical competence and, unless otherwise stated, the contents can be formally referenced. This Serles does not surplant formal journal publication but it does provide the more extensive information required for technological applications (e.g., tabulated numerical data) in a timely manner. 
TABLE OF CONTENTS

Page

ABSTRACT .......................... 3

1. INTRODUCTION ..................... 4

2. RENORHALIZATION OF (N,P) REACTION CROSS SECTION

SETS TO COMPLY WITH ENDF/B-IV CROSS SECTIONS

FOR MONITOR REACTIONS. .................. 6

3. COHPUTATION OF THE RESPONSE OF THRESHOLD REACTIONS

IN REFERENCE FISSION NEUTRON FIELDS. . . . . . . . . 8

4. DISCUSSION OF RESULTS. . . . . . . . . . . . . . 9

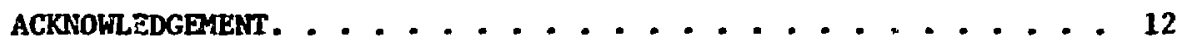

APPENDIX A: PREPARATION AND CALIBRATION OF URANILM

DEPOSITS USED IN THRESHOLD REACTION

MEASUREMERTS. ................... 13

APPENDIX B: ERRATA IN EARLIER REPORTS . . . . . . . . . . 15

REFERENCES ........................... 17

TABLES ............................... 18

FIGURES. . . . . . . . . . . . . . . . . . . 33 


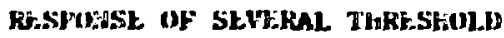

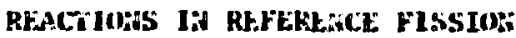

HEUTKOA FHELIn:

by

Innald J. Splth and Jares th. Ifeadows

Arponne dational labnratory, Argonne, 111 inols b11439, L.S.A.

\title{
ABSTRACZ
}

\begin{abstract}
Cross sections for $(n, p)$ reactitons on ${ }^{27} \mathrm{AL}$. $46,47,48_{11}, 54,56$ re, $58_{i i 1}, 54 \mathrm{co}$, and ${ }^{64} \mathrm{zn}$ and for $238_{i}$ fission have been reasured in this leboratory relacive co fission cross sections for $23 j_{l}$ or $238_{1}$, and the results of tinis vork have been reported. These data have been renormalized co accommodate recent revistons of the $235_{b}$ and $238_{l}$ fission evaluated cross sections whicl are accouned for in the ribl/s-IV files. ine response of the renormalized data to tuo comonly used reference neutron fields have been investigated: 1) pure thezmal-neutron fisstion of ${ }^{235} \mathrm{U}$, and 11) the spontaneous fission of ${ }^{252}$ if. The results of this analysts and a conparison wich corresponding recent information from the literature are discussed In this report. Two additional topics are addressed in appendices: i) the preparation and calfbration of uraniu deposits used in cross section measurerencs, and i1) erraca in some earlier reports from our laboratory on this satie peneral subject.
\end{abstract}

*Ths work performed under che ausplces of che u.s. Energy Hesearch and vevelopment Adninistration. 


\section{INTKIDUCTIN:}

bata fron monoenerpetic reasuretents of cross seczion rat los for several $(n, p)$ reactions relative to ${ }^{235}$, or ${ }^{238} u$ fast-neutron fiasion and of the ${ }^{236} v f^{235} t$ fast-neutron fission cross section racto have been reported fron chis laboracory $[1,2,3]$. The results of tile $(n, p)$ reasurenents were exprenaed as final cross seccions hased on togp/b-III values for the appropriate flssion cross sections $\lfloor 1, \ddot{z}, 4]$, while the ${ }^{238}$ vf $f^{235} \mathrm{t}$ fission rat 10 data were reported as ratios [3]. In each instance, the data are very nearly representative of the ronoenergetic quanticies since varinus corrections were applied to compensate for the effects of Int.te geometry, multiple scattering, neutron enerpy spread and secondary neutzon froups (xee Ref. 1 for detalls).

Fye-guide curves were constructed for the $(n, p)$ data which exhibit all sipnificant features of the experimental values but eliminate redurdancy and insfonificant statistical fluctuations. A sufficlent nuber of points were selected from these curves to enable reconstruction of the curves by Interpolation, and these points are listed it Ref. 2 with the desipnation "eviduated cross sestions". The use of the term "evaluated" is probably inappropriace since the curves were not generated from an unblased consideration of all avallable data. The purpose of this exercise uns to provide users of the data witl an unambiguous representation of tite monoenergetic sross sections which could then be used for a variety of applications (e.g., peneration of multgroup cross section sets for zeactor analysis).

Recently, the EwDF/i-IV files have hecore avallable [S] and these crosa sections art ut1lfzed for most current sir plications, at least in the United states. Since our $(n, p)$ reaction data were not explicitly prese. ied in ratio fom (althouph ratios coula be computed from the information provided In Refs. I ani 2), we dectded that it wovld be worth- 
while not only to rahe the ratics avaflahle tuc also to express the $(n, n)$ cress sections in terris of the b:ijr/li-1" fission cross sections. The renortalized cross sections yould be conjrable with otlier data sets in current use.

He chnse to renormalize the eyesulde points for Itclusion in tiuls report. The experiticutal $\sigma_{n p} / 0_{f}$ ratios for the $(I, p)$ reactions ve liave studied have been sent to tine Aational Yeutron cross section certer for inclusion in the IsISks txperimental bata File [6]. hinile users of threshold reaction date for applications (e.p., In fastneutron dosiretry) exploy special forms for representation of the data (e.g., interval-averaped multiproup cross section sets), we chose not to alter the form of presentacion of our results from that used in thef. 2. The reason for this is that different applications call for different representations. Hy making use of point representations of the eyeguide curves and interpolation, coe can penerate data sets in any forn desired.

(lur $(n, p)$ reaction data are intercalibrated since ratios to well-known fission cross sections were measured using a sinple set of uranium deposits and the sane irradiation apparatus for all reactions. Furthermore, the counting. facilities were calibrated using atandaris whose absolute source strengths were measured by coinctdence techniques $[1,2]$. The $(n, p)-t o-f i s s t o n$ cross section ratios depend upon characteristics of reaction product decay. The parameters ihtch we have used are documented in Ref. 2. It was brought to our aticention that a very useful test of our data would be to compute average cross sections for reference neutron fields [7]. The response of activation detectors to reference neutron fields is a standard methed for evaluation and intercalibration of fast-neutron data for reactor dosinetry applisations $[7-10]$. 
Two reference neutron ficlds conxonly usedi for this purpose are: 1) pure tiermal fisston of $235_{t}$ and, it) spontaneous fission of ${ }^{252}$ cf. There are two it.portant reasone for selection of these references. First, it is possthle to produce quite gond approxitutions to these fields eyperimentally. Secordly, the simple forsula

$$
X(E)=C E^{\frac{2}{-5}} \exp (-1.5 E / i \text { av })
$$

provides a pood representation of both these neutron spectra. Grundl and Fisenilauer [11], conducted a very careful evaluation of these fission-neutron spectra and concluded that $\mathrm{Eq}$. (1) best represents tive experimental data for ${ }^{235} \mathrm{U}$ thermal fission when $\mathrm{k}_{\text {av }}=1.47$ tev. l.1kewise, the data for ${ }^{252}$ Cf is vell represented when $L_{\text {av }}=$ $2.13 \mathrm{MeV}$ 1s used. he have Investipaced the response of our $(n, p)$ reaction data $[1$,$] and the { }^{238} \mathrm{U}$ fisston data of Meadows [3] to these standard neutron fields. The results of this analysis are presented in this report.

Two related items are discussed in appendfces of chis report. Appendix A is a detafled discussion of the procedure utilized in preparation of tine uraniun deposits used for all cur measurements. We felt it worthwile to present this information in this renort since the callbration of monitor foils is a very irportant factor to he corsidered In the intercalfbration of data teasured in various laboratories. Appendix B contains errata from Refs. 1 and 2, These are mostly misprints. Ho errors have been found in our data acquisition and processing procedures which would affect the reported values.

\section{RENORHLLZATION UF (N,P) REACTIOS CKOSS SECTION SETS TO COAPLY WITI EHDP/BMIV CROSS SECTIOAS FOR MOKITOR HFACTIOAS}

The cross sections to lie renormalized appear in Tables aII thru $x$ of Kef. 2. The ENHF/b-III fission cross sec- 
thons used previowsly appear in ialsie 1 of thef. 2 . The hibilf/b-It fission cross sections co be used for renormalization appear in Table 1 of tite present report. ihis taible does not contafir all hio livif/i-ly values, lut erely enough to accurately reprouluce che shape of the curve over the encrpy region of incerest for work. The renormalization procedure for the $(n, p)$ cross sections is as follows:

If $\left[\left(E_{1},{ }^{\prime \prime} p_{,}, I I, t\right)\right.$ is a typical set of values from Kef. 2, then for enersy $E_{f}$.

where

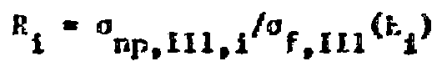

$$
\begin{aligned}
& n_{1}=\text { cross section ratio for energy: }{ }_{1} \\
& \sigma_{F, I I I}\left(H_{i}\right)=\text { fissic } \\
& \text { conputed by linear interpolation of } \\
& \text { appropriate values from Table } 1 \text {, } \\
& \text { Ref. } 2 \text {. }
\end{aligned}
$$

therefore.

$$
{ }_{n n_{1} I V, 1}-R_{1} J_{,} I V\left(t_{1}\right)
$$

yields the renorralized cross seclion, $u_{n p, 1 V_{0}}$ " when

$$
\begin{aligned}
{o_{f, I V}}^{\left(t_{i}\right)=} & \text { fission eross section for enerpy } f_{i}, \text { con- } \\
& \text { puted by linear interpolation of appro- } \\
& \text { priate values from Table } I \text { of the present } \\
& \text { report. }
\end{aligned}
$$

Sets of vilues $\left\{\left(L_{i}, K_{i}, \sigma_{n,}, I v, i\right)\right\}$ resulting fron the renormailzation procedure appenr in Table II thru $x .{ }^{235} \mathrm{y}$ fission cross sections were utilized for all data taken at enerpies below $4 \% \mathrm{ev}$ wh1le ${ }^{238} \mathrm{l}$ fisston cross sections were utilized for hịpher energy data. This is consistent with the measurement procedure [2]. 
It was not necensary to renormalize the $238_{u}$ fission ratio data of Meadous [3]. 236 fission cross sections were computed from these ratio using bivjp/ij-IV ${ }^{235}$ u fisston cross sections. An eyezuide was constructed for these cross section values and points were selected to represent the curve. These points are given in Table XI.

The points In Tables II thru XI represent the various $(n, p)$ reaction cross sections and the ${ }^{238_{v}}$ fission cross section In such a fashion that the cross sections corresponding. to arbitrary energles within the range of the data can be obtained by interpolation. Full loparithic interpolation (see Section IV of Ref. 2 and Vrratur No. 4 of Appendix $b$ in the present report) Is desirable gince it provides a good representation of the cross sections in regions of hifh curvature (e.p.., near threshold) and is nearly equivalent to linear interpolation in regions of gradual variation. However, linear interpolation was utilized for the renormalization procedure because this method was applied to the original experimental data to obtain che cross sections reported in Ref. 2. Computation of $k_{1}$ valuesvia $\mathrm{k}$. (2) represents an "undoing" of part of the original data processing $[1,2\}$ in order to obtain unnormalized ratios. The fact that the orfpinal results were "smoothed" by eyeguides should not invalidate this procedure.

3. COIPUTATION OF THE RESPOASE OF THRESHOLD REACTIONS IN PLFERENCE FISSIOA NGUTRUI: FIELDS

The response of the renormalized $(n, p)$ cross sections and Meadows ${ }^{238} \mathrm{U}$ fission cross sections, based on $\mathrm{kAJF} / \mathrm{b}-\mathrm{IV}$ monitor cross sections, was investigated and the results are presented in this section.

For reaction process "f", let

$$
\bar{\sigma}_{j}\left(E_{a v}, F_{\min }, F_{\max }\right) \equiv \int_{E_{\min }}^{E_{\max }} d E x(E) \sigma_{j}(E) \text {. }
$$


where the monoenergetic cross section is $\sigma(E)$, and, if $X(E)$ is given by Eq. 1, the constant $C$ is chosen to yield the desired normalization

$$
\int_{0}^{\infty} d E x(E)=1
$$

clearly,

$$
\bar{\sigma}_{j}\left(E_{a v}, E_{m i n}, E_{\max }\right)<\bar{\sigma}_{j}\left(E_{a v}, 0, \infty\right) .
$$

Iet

$$
\left\langle\sigma_{j}\right\rangle \equiv \bar{\sigma}_{j}\left(E_{a v}, 0, \infty\right)=\text { spectrum averaged cross section. }
$$

The quantity $\left\langle\sigma_{j}\right\rangle$ has been given the designation $\bar{\sigma}_{f}(x, j)$ by Grund1 (e.8., Ref. 11) when $X$ represents a fission neutron field. This notation appears to be sidely accepted so we w111 comply with it in this report.

A point worthy of mention is summarized by $\mathrm{Dq}_{\mathrm{q}}$. (G). It Is only meaningful to compare spectrum-averaged cross sections computed from monoenergetic data with the results of integral measurements where the monoenergetic data span essentially all of the response region of the reaction. A plot of the function $X(E) \sigma_{j}(E)$ provides a clear indication of whether this criterion is satisfied for a particular set of Iimits ( $E_{\text {min }}, E_{\text {max }}$ ).

The result:s of our analysis appear in Figs. 1 thru 10 and are sunmar1zed in Table XII. It is clear from the figures that our data from near threshold to $10 \mathrm{MeV}$ covers essentially all of the response fior the (n ) reactions on ${ }^{27} \mathrm{Al},{ }^{47} \mathrm{Ti},{ }^{54} \mathrm{Fe},{ }^{58} \mathrm{yi}$ and ${ }^{64}$, and for we fission of ${ }^{238} \mathrm{v}$. The same cannot be sald fc the $(n, p)$ reactions on ${ }^{46,48} \mathrm{TI},{ }^{56} \mathrm{Fe}$ and ${ }^{59} \mathrm{Co}$. These qualitative coments apply for both reference fission neutron fields.

\section{DISCUSSION OF RESULTS}

Values of $\bar{\sigma}\left(E_{a v}, E_{\min }, E_{\max }\right)$ lirom our work are compared with some representative results from the literature $[5,9,10]$ in Table XIII. We Indicate by (....) those values correspond- 
Ing to innomplete intepration of the response function. orhervice, it is clear that our resulte for ${ }^{235}$ u therral fisaton are in quice good agreement wth recent values from the literature. The values reported by Fabry (10) result from an evaluation of Intepral data. The values labelled EN] the evaluateu cross sections in that file in a spectru defined by Eq. (1) with $E_{\text {av }}=1.98 \mathrm{MeV}$ (which is sliphtly different from the ${ }^{235}$ thermal fission spectrom of frund and kisenhauer [11]). The evaluated values of Sinons and McElroy are soncwhat out of date now, but i'ley have been Included because the report which contains then 15 often referenced [9].

We have not assipned uncertainties to our averaged cross sections; however, In view of the quoted accuractes of the ortginal data $[1,2]$ it would seew that $10 \%$ is a reasonable upper 1inte. Considering the cross section uncertainties, our results appear to be entirely consistent with the evaluation by Fabry [11] and the ENIJ!B-IV values [5,13]. A closer Inspection of Table XIII and Figs. 1 thru 10 proripts us to offer the following subjective observations:

1) Generally, our results are in betcer agreement with the ENDF/li-IV integral values [10]. An exception is the ${ }^{27} \mathrm{Al}(n, p){ }^{27} \mathrm{~s}$, reaction. In view of the probable overlappling of error bars, the differences may not be simificant.

11) The shapes of the renormalized cross section curves In the vicinity of 5-7 MeV seer somewhat odd. This is particula ly noticeahle for reactions where the cross section is relatively flat at these energies (a pood example is the ${ }^{54} \mathrm{Fe}(\mathrm{n}, \mathrm{p})^{54}$ in reaction, Fir. 5). It is not hard to see why this occurs. These are noticealsle differences in tive $\mathrm{kNWF/B-III}$ and IV cross sections for ${ }^{238} v$ fission for the repion of 
3-7 \%"y. Furthermofe, the ${ }^{238}$ u fission cross section increases rapidy with energy between 5 and 7 MeV. Wie note that the shape peculiarity involves differences of a $6 \%$ which are prohably within the experimental uncerhinties. Nevertheless, we feel that it is importarit to investifate the consequenezs of using kNW/b-TV cross sections on the shapes of excitation functiofs since there effects are generally hidden then cóminarisons are based only upon Integral data. wohoenergetic measurements are the only reliable methbd for investipation of excitation function structuret Reprettably, there is very litele systenatic work bobing done in this inportant area.

111) The need for acdithicnal $(n, p)$ reaction data for $46,48 \mathrm{T1}$. $56_{\text {Fe and }} 59$ co is apparent from our response curves. For vartous experimental reasons, these would be difficult measiurenents to make.

1v) There are no qualitative differences in the responsen of the shreshold reactions we have studied insofar as the two referenć fission neutron fields are concerned. The ${ }^{252}$ (if spec: a is harder and consequently, the results of an ain ce of data above 10 teV are more noticeable. An advantage of the ${ }^{252}$ cif source is that measurements can be made siclout reactors and the carefully designed irradiation cavities which are required to simulate the ${ }^{235_{\mathfrak{V}}}$ pure themal fission field. 


\section{ACKWOWLEDGEHENT}

We are Indebted to Dr. J. A. Grund1 for some valrable suggestlons he provided during a recent meeting with one of the authors (DLS). 


\section{APPENDIX A}

\section{PREPARATION AND CALIBRATION OF LRANIUA DEPOSITS USED IN \\ THRESHOLD RFACTION MFASITREMERTS}

Most of the urantum deposits were prepared by vacuum evaporation of UF $4^{*}$ Masking plates with $2.54-\mathrm{cm}$ dia. holes were positioned in the vacuun chamber so that they were perpendicular to the lise connecting the boat containing the $\mathrm{UF}_{4}$ and the center of the hole. Distances ranged from 9 to $17 \mathrm{~cm}$. Deposits were made on platinum, molybdenum or stainless steel. All plates had polished surfaces. They vere thoroughly degreased and clamped tightly against the masks. Any deposits which appeared to have any problems with adherence of the evaporated material were discarded. Deposit thicknesses up to $1 \mathrm{mg} / \mathrm{cm}^{2}$ were readily obtained in this way.

Since the evaporation method involved a large amount of waste, it was only used for materfals which were in good supply. Deposits of other materials were prepared by electroplating. The unfformity of the ellectroplated depostts was not as good and adherence was poos for deposits thicker than $\imath 0.5 \mathrm{mg} / \mathrm{cm}^{2}$.

$235 \mathrm{u}$ Deposits

Tfhe mass analysis of the material used in fabricating the ${ }^{235} \mathrm{U}-$ enriched deposits, given in Table XIV, is the result of three separate determinations: two conducted at Argonne National Laboratory, Illinois, and one at Argonne National Laboratory-West, Idaho. The errors are based on the scatter of the results or the quoted precision, whichever is larger. Ten 2.54-cm dia deposits on $0.13 \mathrm{~m}$ thick platinum backIngs were prepared by vacuum evaporacton. Depostt masses ranged from $\sim 0.48$ to $\sim 2.5 \mathrm{mg}$. They were counted in both low-geonetry and $2 \pi$ alpha counters. The geometry factor of the low-geonetry counter was $222.9 \pm 0.7$. Most of the error arose from the uncertainty in the thickness of the platinum and the difficulty of getting the soft 
material to lfo flat against the support plate. A comparison of the low-geometry and $2 \pi$ count rates indicated that a $2.6 \pm 0.2 \%$ correction was required for back scattering from the platinum backing at zero deposit thickness. The deposits were dissolved frow the backings and the amount of urantum determined by colorimetric comparison to standard solutions. The error, as determined from the difference of duplicate measurements, was $\sim 0.5 \%$.

The specific activity computed from the above Information was $2.065 \pm 0.011 \mathrm{~d} / \mathrm{sec} / \mu \mathrm{g}$. The calculated spectfic activity, based on recent half-1ife determinations $[14-16]$, 1s $2.043 \pm 0.015 \mathrm{~d} / \mathrm{sec} / \mathrm{Hg}$, a difference of $1.1 \%$.

The ${ }^{235}$ U-enriched deposits used for neutron monitoring were prepared by evaporating the above-mentioned material onto 0.25-mm thick, polished stainless steel plates. Ten 2.54-cm dia deposits were initially prepared with thicknesses ranging from 80 to 2365 $\mu g / \mathrm{cm}^{2}$. These deposits vere counted in a low-geometry counter with a geometry factor of $221.7 \pm 0.7$ and also in a $2 \pi$ counter. Comparison of the two count rates indicated a back scattering correction of 0.97 , In gocd agreement with the results for platinum, considering the difference in atoric number of the backing waterials. The masses of each of the deposits are based on the low-geometry counts and the spectfic activity of the material used in fabrication.

238.

Deposits

The ${ }^{238} \mathrm{U}$ deposits were prepared from depleted uranium and since the activity was too low for counting in a low-geometry counter all counting was done in the $2 \pi$ counter. Several $2.54-\mathrm{cm}$ dia deposits were made by vacuum evaporation of $\mathrm{UF}_{4}$ on $0.13-m$ nolybdenum plates. $A 11$ were counted $I n$ a $2 \pi$ counter and six were analyzed colorimetrically to determine the amount of uranium present. The mass of the material and the $2 \pi$-count rate are related by

$$
\mathbf{W}=\mathbf{R} /(\mathbf{A}+\mathbf{b} \mathbf{R})
$$

where

$$
\begin{aligned}
& W=\text { mass of uranium } \\
& R=2 \pi \text {-count rate } \\
& a=0.5413 \pm 0.0027 \\
& b=-0.0154 \pm 0.0015
\end{aligned}
$$


other ${ }^{238} \mathrm{v}$ deposfts were prepared from material containing only

$6 \mathrm{ppm}$ inpurities. Here, the activity was too low to wake its accurate counting practical so the amount of uranium in the deposits was deterwined by a comparison of the fission rates with those of other calibrated deposits. Such comparisons were made with both ${ }^{235} \mathrm{D}$-enriched and ${ }^{238} U$ deposits using a technique described elsewhere $[3]$.

Several of the deposits used in $(n, p)$ cross section measurements were also used in weasurement of the ${ }^{238} \mathrm{u} / /^{235} \mathrm{v}$ fission cross section rat10, and the results were in good agreement with fission cross section ratio measurements performed using deposits whose wasses ware determined by an independent wethod [3].

The calibrated uranium deposits used in threshold reaction cross section measurements in our laboratory are recounted at various intervals to insure that no uranium is physically last wth the passage of $t$ me.

\section{APPEIDIX B}

ERRATA IN EARLIER REPORTS

The results of our work related to the measurement of $(n, p)$ reaction cross sections have been made avallable in tro reports 1 ssued from this laboratory $[1,2]$. Corrections for some errors found in these reports are presented in this appendix.

Erratum No. 1: Report ANL-79a9 [1].

Eq. (C.4) In Appendix C should read:

$$
\theta_{S k \ell}=\frac{\theta_{S \ell}^{\max }}{N_{D}}\left(k-\frac{1}{2}\right)
$$

Erratum No. 2: Report ANL-7989 [1].

Ref. 5 should read:

5. A. M. Bresesti, M. Bresest1, A. Rota, R. A. Rydin and L. Lesca, Nuc1. Sci. Eng. 40, 331 (1970). 
Erratue No. 3: Report ANL-7989 [1].

Ref. 13 should read:

13. S. A. Cox and P. R. Hanley, "Performance of the ANL Dynamitron Tanden," IEE Trans. Nuc1. Sc1. 18, 108 (1971).

Erratum No. 4: Report ANL/NDM-10 [2].

Eqs. (2) and (3) should read:

$a=\left(\ln E_{2} \ln \sigma_{1}-\ln E_{1} \ln \sigma_{2}\right) /\left(\ln E_{2}-\ln E_{1}\right)$

$b=\left(\ln \sigma_{2}-\ln \sigma_{1}\right) /\left(\ln E_{2}-\ln E_{1}\right)$

Erratu No. 5: Report ANL/MD:-10 [2].

Ref. 11 should read:

11. S. A. Cox and P. R. Hanley, IEE Trans. Nuc1. Sc1. 18, 108 (1971). 


\section{REFERENCES}

1. Donald L. Smith and James W. Meadow5, Report ANL-7989, Argonne Nationa1 Laboratory (1973).

2. Donald L. Smith and James H. Meadows, Report ANL/NDM-10, Argonme National Laboratory (1975) :

3. J. W. Headows, Nucl. Sc1. Eng. 49, 310 (1972). Also, an additional paper has been accepted for publication in Nuc1. Sc1. Eng. and w11 be published in the near future.

4. Evaluated Neutron Ilata FIIe, ERDF/B-III, National Neutron Cross Section Center, Brookhaven National Laboratory.

5. Evaluated Neutron Data File, ENDF/B-IV, National Neutron Cross Section Center, Brookhaven National Laboratory.

6. Experimental Data File, CSISRS, National Neutron Cross Section Center, Brookhaven National Laboratory.

7. J. A. Grund1, National Bureau of Standards, Washington, D. C. U.S.A. (Private communication).

8. A. M. Bresest1, M. Bresest1, A. Rota, R. A. Rydin and L. Lesca, Nucl. Si:1. Eng. 40,331 (1970).

9. R. L. Simons and W. N. McElroy, Report BHh-1312, Battelle Northwest Laboratories (1970).

10. A. Fabry, Report BLG-465, Centre d'Etude de 1'Energe Nucleaire (1972).

11. J. Grund1 and C. Eisenhauer, Bull. Am. Phys. Soc. 20, 145 (1975).

12. B. E. Watt, Phys. Rev. 97, 1037 (1952).

13. B. A. Magurno and O. Ozer, Nucl. Tech. 25, 376 (1975).

14. P. de Bièvre, K. F. Lauer, H. Moret, G. Htischenborin, J. Spaepen, A. Spernol, R. Vaninbroukx and V. Verdingh from Chemical tuclear Data Measurements and Methods. British Nuclear Energy Society, p 49-50, 20-22 September 1971.

15. A. H. Jaffey, K. F. Flynn, L. E. Glendenin, W. C. Bently and A. . Essling, Phys. Rev. C4, 1889 (1971).

16. K. F. Flynn, A. H. Jaffey, H. C. Bentley and A. M. Essiling, J. Inorg. Nuc1. Chem. 34, 1121 (1972). 
Table I

ENDF/B-IV Fission Cross Sections ${ }^{a}$

A. ${ }^{235} v(n, f)$ Cross Sections

\begin{tabular}{|ll|cc|cr|}
\hline $\begin{array}{c}E_{n} \\
(M e V)\end{array}$ & $\begin{array}{c}\sigma_{F} \\
(\text { barn })\end{array}$ & $\begin{array}{c}E_{n} \\
(M e V)\end{array}$ & $\begin{array}{c}\sigma_{F} \\
(\text { barn })\end{array}$ & $\begin{array}{c}E_{n} \\
(M e V)\end{array}$ & $\begin{array}{c}\sigma_{F} \\
\text { (barn) }\end{array}$ \\
\hline 0.1 & 1.585 & 1.4 & 1.25 & 6.7 & 1.445 \\
0.15 & 1.458 & 1.6 & 1.258 & 7.0 & 1.549 \\
0.2 & 1.351 & 1.8 & 1.267 & 7.5 & 1.682 \\
0.25 & 1.308 & 2.0 & 1.274 & 8.0 & 1.758 \\
0.3 & 1.28 & 2.5 & 1.275 & 9.0 & 1.804 \\
0.4 & 1.216 & 3.0 & 1.232 & 10.0 & 1.768 \\
0.5 & 1.172 & 4.0 & 1.15 & 11.0 & 1.718 \\
0.6 & 1.152 & 5.0 & 1.094 & 12.0 & 1.767 \\
0.7 & 1.135 & 5.5 & 1.059 & 13.0 & 1.976 \\
0.8 & 1.133 & 5.75 & 1.075 & 14.0 & 2.152 \\
0.9 & 1.174 & 6.0 & 1.16 & 15.0 & 2.23 \\
1.0 & 1.225 & 6.2 & 1.232 & & \\
1.2 & 1.258 & 6.5 & 1.358 & & \\
\hline
\end{tabular}

B. ${ }^{238} U(n, f)$ Cross Sections

\begin{tabular}{|ll|ll|ll|ll|}
\hline $\begin{array}{c}E_{n} \\
(M e V)\end{array}$ & $\begin{array}{c}\sigma_{F} \\
(b a r n)\end{array}$ & $\begin{array}{c}E_{n} \\
(M e V)\end{array}$ & $\begin{array}{c}\sigma_{F} \\
(\text { barn })\end{array}$ & $\begin{array}{c}E_{n} \\
(M e V)\end{array}$ & $\begin{array}{c}\sigma_{F} \\
\text { (barn) }\end{array}$ & $\begin{array}{c}E_{n} \\
(M e V)\end{array}$ & $\begin{array}{c}\sigma_{F} \\
\text { (barn) }\end{array}$ \\
\hline 0.1 & $0.4 \times 10^{-4}$ & 0.92 & 0.01278 & 1.35 & 0.0933 & 2.5 & 0.555 \\
0.3 & $0.7 \times 10^{-4}$ & 0.95 & 0.0163 & 1.4 & 0.1512 & 2.75 & 0.55 \\
0.5 & $0.234 \times 10^{-3}$ & 0.97 & 0.01609 & 1.45 & 0.228 & 3.0 & 0.542 \\
0.575 & $0.566 \times 10^{-3}$ & 1.0 & 0.01617 & 1.5 & 0.294 & 3.5 & 0.555 \\
0.61 & 0.00124 & 1.05 & 0.01812 & 1.6 & 0.382 & 4.0 & 0.566 \\
0.7 & 0.00334 & 1.1 & 0.0235 & 1.7 & 0.437 & 4.5 & 0.563 \\
0.75 & 0.001985 & 1.15 & 0.0349 & 1.8 & 0.481 & 5.0 & 0.555 \\
0.8 & 0.003116 & 1.2 & 0.0405 & 1.9 & 0.514 & 5.2 & 0.560 \\
0.85 & 0.005871 & 1.25 & 0.0426 & 2.0 & 0.535 & 5.4 & 0.563 \\
0.89 & 0.008716 & 1.3 & 0.0577 & 2.1 & 0.545 & 5.5 & 0.566 \\
\hline
\end{tabular}


Table I (Contd.)

B. ${ }^{238} U(n, f)$ Cross Sections

\begin{tabular}{|cc|cc|cc|cc|}
\hline $\begin{array}{c}\mathrm{E}_{\mathrm{n}} \\
(\mathrm{MeV})\end{array}$ & $\begin{array}{c}\sigma_{F} \\
(\text { barn })\end{array}$ & $\begin{array}{c}\mathrm{E}_{\mathrm{n}} \\
(\mathrm{MeV})\end{array}$ & $\begin{array}{c}\sigma_{F} \\
(\text { barn })\end{array}$ & $\begin{array}{c}\mathrm{E}_{\mathrm{n}} \\
(\mathrm{MeV})\end{array}$ & $\begin{array}{c}\sigma_{F} \\
(\text { barn })\end{array}$ & $\begin{array}{c}\mathrm{E}_{\mathrm{n}} \\
(\mathrm{MeV})\end{array}$ & $\begin{array}{c}\sigma_{F} \\
\text { (barn) }\end{array}$ \\
\hline 5.8 & 0.603 & 7.5 & 6.978 & 10.0 & 0.974 & 17.0 & 1.34 \\
6.0 & 0.661 & 8.0 & 0.99 & 11.0 & 0.983 & 18.0 & 1.32 \\
6.2 & 0.727 & 8.25 & 0.996 & 12.0 & 0.995 & 19.0 & 1.3 \\
6.5 & 0.835 & 8.5 & 1.0 & 13.0 & 1.048 & 20.0 & 1.435 \\
6.8 & 0.897 & 8.75 & 0.997 & 14.0 & 1.14 & & \\
7.0 & 0.93 & 9.0 & 0.992 & 15.0 & 1.26 & & \\
7.2 & 0.957 & 9.5 & 0.982 & 16.0 & 1.32 & & \\
\hline
\end{tabular}

${ }^{\text {Ref. 5. }}$ 
Cross Sections for the ${ }^{27} \mathrm{~A} 2(\mathrm{n}, \mathrm{p})^{27} \mathrm{Mg}$

Reaction Based on an Eyegutde to Experimental

Data and ENDP/B-IV Fission Cross Sections

A. ${ }^{235}$ y Monitor

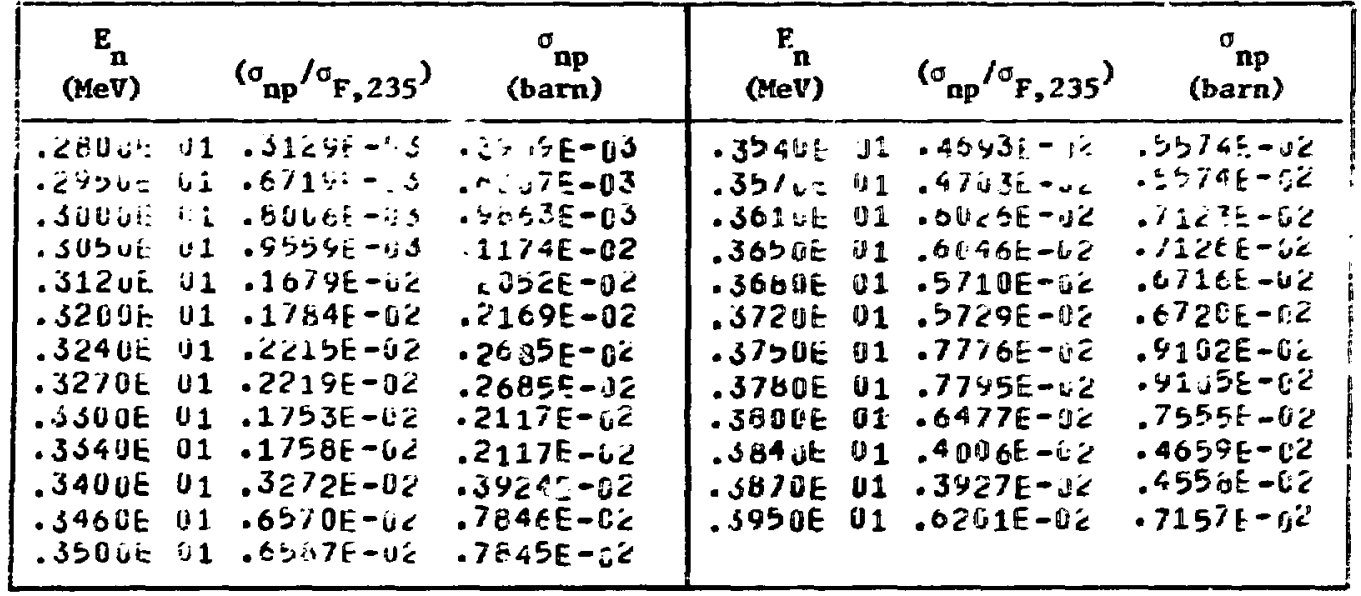

B. ${ }^{238} \mathrm{U}$ Monttor

\begin{tabular}{|c|c|c|c|c|c|c|c|}
\hline$\underset{(\mathrm{MeV})}{E_{n}}$ & & $\left(\sigma_{n p} / \sigma_{F, 238}\right)$ & $\underset{\text { (barn) }}{\sigma_{\mathrm{np}}}$ & $\underset{\mathbf{n}}{\left.\mathbf{E}_{\mathbf{n}} \mathbf{V}\right)}$ & & $\left(\sigma_{n p} / \sigma_{F, 238}\right)$ & $\underset{\text { (barn) }}{\sigma_{n p}}$ \\
\hline 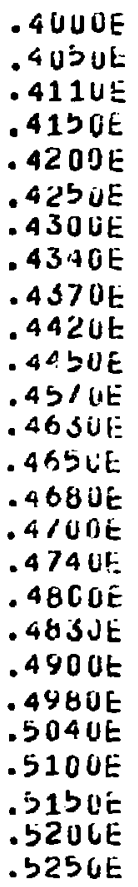 & 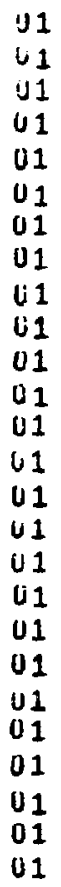 & $\begin{array}{l}.1330 E-01 \\
.1237 E-2 \\
.5557 E-02 \\
.4557 E-i 12 \\
.1312 E-01 \\
.1686 E-11 \\
.2154 E-C 1 \\
.2154 E-11 \\
.2123 E-01 \\
.21<3 E-01 \\
.2248 E-01 \\
.3054 E-11 \\
.3643 E-11 \\
.3318 E-01 \\
.3651 E-01 \\
.3469 E-01 \\
.3469 E-01 \\
.2532 E-61 \\
.2533 E-01 \\
.3566 E-01 \\
.5257 E-01 \\
.5258 E-01 \\
.4934 E-01 \\
.5424 E-01 \\
.5545 E-01 \\
.5207 E-01\end{array}$ & $\begin{array}{l}.7528 E-02 \\
.6518 F E-02 \\
.5403 E-02 \\
.3401 E-02 \\
.74111 E-02 \\
.9517 E-0 E \\
.1215 E-01 \\
.1215 E-01 \\
.114 \pm E-01 \\
.1147 E-01 \\
.1266 E-01 \\
.2053 E-01 \\
.2071 E-01 \\
.166 j E-01 \\
.1538 E-01 \\
.1991 E-01 \\
.1541 E-01 \\
.1413 E-01 \\
.1413 E-01 \\
.1935 E-01 \\
.2919 E-01 \\
.2923 E-111 \\
.2751 E-01 \\
.3031 E-01 \\
.3133 E-01 \\
.2520 E-01\end{array}$ & $\begin{array}{l}.5280 E \\
.5330 E \\
.5370 E \\
.5420 E \\
.5450 E \\
.5470 E \\
.5500 E \\
.5525 E \\
.5575 E \\
.5625 E \\
.5675 E \\
.5710 E \\
.5740 E \\
.5800 E \\
.5875 E \\
.0000 E \\
.6250 E \\
.6500 E \\
.7000 E \\
.7500 E \\
.8000 E \\
.8500 E \\
.9000 E \\
.9500 E \\
.1000 E\end{array}$ & $\begin{array}{l}01 \\
01 \\
01 \\
01 \\
01 \\
01 \\
01 \\
01 \\
01 \\
01 \\
01 \\
01 \\
01 \\
01 \\
01 \\
01 \\
01 \\
01 \\
01 \\
01 \\
01 \\
01 \\
01 \\
01 \\
02\end{array}$ & 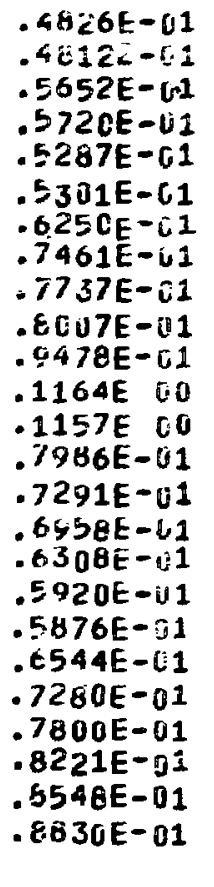 & $\begin{array}{l}.2708 E-01 \\
.2704 E-01 \\
.3160 E-01 \\
.3224 E-01 \\
.2985 E-01 \\
.2976 E-01 \\
.3537 E-01 \\
.4246 E-01 \\
.4451 E-01 \\
.4655 E-01 \\
.5569 E-01 \\
.6895 E-01 \\
.6891 E-01 \\
.4816 E-01 \\
.4555 E-01 \\
.4599 E-01 \\
.4679 E-01 \\
.4943 E-01 \\
.5465 E-01 \\
.6400 E-01 \\
.7207 E-01 \\
.7800 E-01 \\
.8155 E-01 \\
.8394 E-01 \\
.3600 E-01\end{array}$ \\
\hline
\end{tabular}


Table III

Cross Sections for the ${ }^{46} \mathrm{TI}(\mathrm{n}, \mathrm{p})^{46} \mathrm{Sc}$

Reaction Based on an Eyeguide to Experimental

Data and ENDF/B-IV Fission Cross Sections

A. ${ }^{235} \mathrm{v}$ Monitor

\begin{tabular}{|c|c|c|}
\hline$\underset{(\mathrm{MeV})}{\mathbf{E}_{\mathbf{n}}}$ & $\left(\sigma_{n p} / \sigma_{F, 235}\right)$ & $\underset{\text { (barn) }}{\sigma_{\text {np }}}$ \\
\hline $\begin{array}{l}.360 \text { UE U1 } \\
.3900 E \text { U1 }\end{array}$ & $\begin{array}{l}-1091 t-01 \\
.1700 E-01\end{array}$ & $\begin{array}{l}.129 r E-81 \\
.1569 E-01\end{array}$ \\
\hline
\end{tabular}

B. ${ }^{238}$ U Monitor

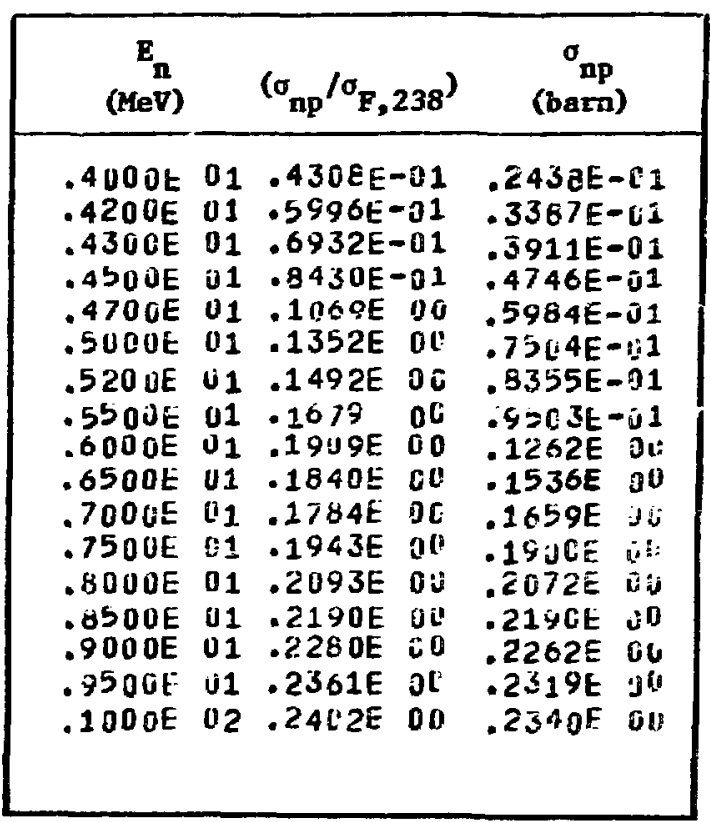


Cross Sections for the ${ }^{4 T} \mathbb{T I}(\mathbb{R}, \mathbb{p})^{4 T} \mathrm{Sc}$

Reacsion Based on an Eyeguide to Experimental

Data and ENDF/B-IV Fission Cross Sections

A. $235 \mathrm{U}$ Monitor

\begin{tabular}{|c|c|c|c|}
\hline $\begin{array}{r}\mathbf{E}_{\mathbf{n}} \\
(\mathrm{MeV})\end{array}$ & & $\left(\sigma_{\mathrm{np}} / \sigma_{\mathrm{F}, 235}\right)$ & $\underset{\text { (barn) }}{\sigma{ }^{\circ}}$ \\
\hline $\begin{array}{l}.4140 E \\
.1150 E \\
.1250 E \\
.1300 E \\
.1300 E \\
.1600 E \\
.10100 \\
.2000 E \\
.2100 E \\
.2200 E \\
.2500 E \\
.25310 E \\
.2410 E \\
.26002 \\
.2100 E \\
.2900 E \\
.3100 E \\
.3300 E \\
.3200 E \\
.3800 E\end{array}$ & 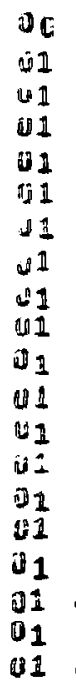 & $\begin{array}{l}.2078 E-04 \\
.5154 E-03 \\
.2338 E-02 \\
.2576 E-02 \\
.3128 E-02 \\
.3887 E-02 \\
.6756 E-02 \\
.3105 E-02 \\
.1333 E-01 \\
.1602 E-01 \\
.229 E-01 \\
.2450 E-01 \\
.2475 E-01 \\
.2351 E-01 \\
.2414 E-01 \\
.2348 E-01 \\
.353 E-01 \\
.4191 E-01 \\
.4854 E-01 \\
.5541 E-01\end{array}$ & 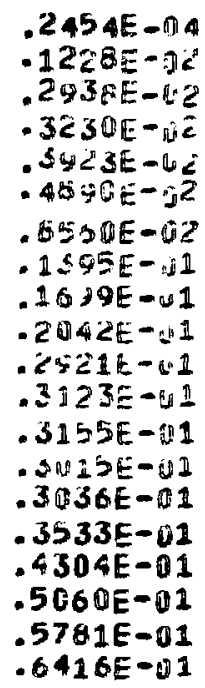 \\
\hline
\end{tabular}

B. ${ }^{238} \mathrm{v}$ Monftor

\begin{tabular}{|c|c|c|c|}
\hline$\underset{(\mathrm{MeV})}{\mathbf{E}_{\mathbf{n}}}$ & & $\left(\sigma_{n p} / \sigma_{F, 238}\right)$ & $\underset{\text { (barn) }}{\sigma_{\text {np }}}$ \\
\hline 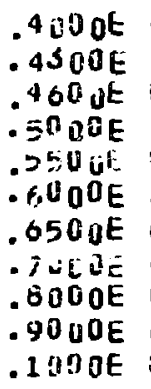 & \begin{tabular}{l}
$u_{1}$ \\
$y_{1}$ \\
$j_{1}$ \\
$j_{1}$ \\
$\vdots 1$ \\
$j 1$ \\
$u_{1}$ \\
\hdashline$\vdots$ \\
$u_{1}$ \\
01 \\
01
\end{tabular} & 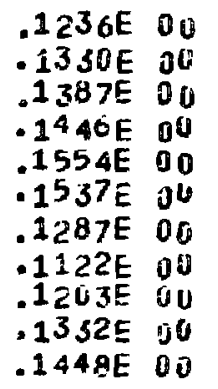 & 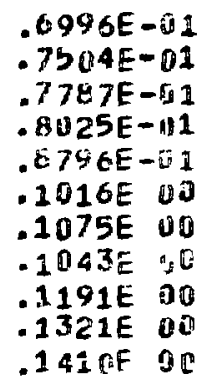 \\
\hline
\end{tabular}


Table V

Cross Sectlons for the ${ }^{4 B} \mathrm{~T} 1(\mathrm{n}, \mathrm{p})^{48}$ sc Reaction Based on an Eyeguide to Experimental Data and ENDF/B-IV Fiasion Cross Sections for ${ }^{238_{U}}$

\begin{tabular}{|c|c|c|c|}
\hline$\underset{(M e V)}{E_{n}}$ & & $\left(\sigma_{n p} / \sigma_{F, 238}\right)$ & $\underset{\text { (barn) }}{\sigma_{\text {np }}}$ \\
\hline $\begin{array}{l}.4700 E \\
.4900 E \\
.2000 E \\
.5100 E \\
.5150 E \\
.2200 E \\
.5 .00 E \\
.5300 E \\
.5500 E \\
.5600 E \\
.5700 E \\
.5900 E \\
.6000 E \\
.6200 E \\
.6500 E \\
.7000 E \\
.7500 E \\
.8000 E \\
.8500 E \\
.9000 E \\
.9500 E \\
.1000 E\end{array}$ & $\begin{array}{l}01 \\
01 \\
01 \\
01 \\
91 \\
01 \\
01 \\
01 \\
01 \\
01 \\
01 \\
01 \\
01 \\
01 \\
01 \\
01 \\
01 \\
01 \\
01 \\
01 \\
01 \\
02\end{array}$ & $\begin{array}{l}.4312 E-06 \\
.1314 E-05 \\
.1634 E-03 \\
.1792 E-03 \\
.2601 E-03 \\
.3264 E-03 \\
.4652 E-03 \\
.574 A E-03 \\
.8571 E-03 \\
.9097 E-03 \\
.1132 E-02 \\
.2441 E-02 \\
.2913 E-02 \\
.3521 E-02 \\
.4762 E-02 \\
.6944 E-02 \\
.1022 E-01 \\
.1345 E-01 \\
.1640 E-01 \\
.2017 E-01 \\
.2391 E-01 \\
.2875 E-01\end{array}$ & $\begin{array}{l}.2414 E-04 \\
.7314 E-04 \\
.6069 E-04 \\
.7535 E-04 \\
.1118 E-63 \\
.1028 E-03 \\
.2608 E-05 \\
.3228 E-03 \\
.4851 E-03 \\
.5261 E-03 \\
.6686 E-05 \\
.1543 E-02 \\
.1925 E-02 \\
.2546 E-32 \\
.5476 E-02 \\
.6458 E-02 \\
.9995 E-02 \\
.1332 E-01 \\
.1640 E-01 \\
.2001 E-01 \\
.2348 E-01 \\
.2800 E-01\end{array}$ \\
\hline
\end{tabular}


Table VI

Cross Sections for the ${ }^{54} \mathrm{Fe}(n, p){ }^{54} \mathrm{Mn}$

Reaction Based on an Eyeguide to Experimental

Data and ENDF/B-IV Fission Cross Sections

A. ${ }^{235} \mathbf{v}$ Monitor

\begin{tabular}{|c|c|c|c|}
\hline $\begin{array}{c}\mathbf{E}_{\mathbf{n}} \\
(\mathrm{MeV})\end{array}$ & & $\left(\sigma_{n p} / \sigma_{E, 235}\right)$ & $\stackrel{\sigma_{n p}}{\text { (barn) }}$ \\
\hline $\begin{array}{l}.2000 E \\
.2200 E \\
.2400 E \\
.2600 E \\
.2700 E \\
.2800 E \\
.3000 E \\
.3200 E \\
.3400 E \\
.3500 E \\
.5600 E \\
.3700 E \\
.3900 E\end{array}$ & $\begin{array}{l}y_{1} \\
01 \\
01 \\
01 \\
v_{1} \\
01 \\
0_{1} \\
u_{1} \\
v_{1} \\
01 \\
u_{1} \\
u_{1} \\
v_{1}\end{array}$ & $\begin{array}{l}.1065 E-01 \\
.1907 E-01 \\
.353 \text { E-01 } \\
.5855 E-01 \\
.7516 E-01 \\
.9147 E-01 \\
.1089 E 00 \\
.13 \angle 5 E 00 \\
.1722 E \text { 00 } \\
.1993 E \text { 00 } \\
.2112 E \text { 00 } \\
.2200 E \text { OU } \\
.2353 E \text { OU }\end{array}$ & $\begin{array}{l}.1337=-01 \\
.243 J E-01 \\
.4512 E-01 \\
.7415 E-01 \\
.9456 E-01 \\
.1143 E \text { 0 } \\
.1342 E \\
.1611 E \\
.2065 E \\
.2374 E \\
.2448 E \\
.2584 E \\
.2725 E\end{array}$ \\
\hline
\end{tabular}

B. ${ }^{238}$ U Monitor

\begin{tabular}{|c|c|c|c|}
\hline $\begin{array}{c}E_{n} \\
(M e V)\end{array}$ & & $\left(\sigma_{\mathrm{np}} / \sigma_{\mathrm{F}, 238}\right)$ & $\begin{array}{c}\sigma_{\text {np }} \\
\text { (barn) }\end{array}$ \\
\hline $\begin{array}{l}.4100 E \\
.4500 E \\
.2000 E \\
.0300 E \\
.5600 E \\
.6100 E \\
.6500 E \\
.7000 E \\
.8500 E \\
.100 E\end{array}$ & $\begin{array}{l}0_{1} \\
01 \\
01 \\
01 \\
0_{1} \\
01 \\
01 \\
01 \\
0_{1} \\
02\end{array}$ & $\begin{array}{l}.5247 E \text { OU } \\
.6257 E \text { OL } \\
.7510 E \text { OU } \\
.8010 E \text { OU } \\
.7960 E \text { OU } \\
.7202 E \text { OU } \\
.6049 E \text { OU } \\
.5021 E \text { OO } \\
.4650 E \text { OU } \\
.4723 E \text { OU }\end{array}$ & $\begin{array}{l}.2967 E \text { OU } \\
.3523 E \text { OO } \\
.4168 E \\
.4498 E \text { OO } \\
.4604 E \text { OD } \\
.4984 E \text { OO } \\
.5051 E \text { OD } \\
.4672 E \text { OO } \\
.4650 E \text { O } \\
.4600 E \text { OO }\end{array}$ \\
\hline
\end{tabular}


Cross Sections for the ${ }^{56} \mathrm{Fe}(\mathrm{n}, \mathrm{p})^{56} \mathrm{Mn}$ Reaction Based on an Eyeguide to ExperimentaI Data and ENDE/B-IV Fission Cross Sections for ${ }^{238} \mathrm{y}$

\begin{tabular}{|c|c|c|c|}
\hline$\underset{(M e V)}{g_{n}}$ & & $\left(\sigma_{n p} / \sigma_{F, 238}\right)$ & $\underset{\text { (barn) }}{\sigma_{n p}}$ \\
\hline $\begin{array}{l}.4000 \mathrm{E} \\
.4200 \mathrm{E} \\
.4300 \mathrm{E} \\
.4500 \mathrm{E} \\
.4700 \mathrm{E} \\
.4600 \mathrm{E} \\
.4900 \mathrm{E}\end{array}$ & $\begin{array}{l}01 \\
01 \\
01 \\
01 \\
01 \\
01 \\
01 \\
01 \\
01\end{array}$ & $\begin{array}{l}.1161 E-04 \\
.4216 E-04 \\
.0431 E-04 \\
.2585 E-03 \\
.6844 E-53 \\
.1059 E-02 \\
.1408 E-02 \\
.1784 E-02\end{array}$ & $\begin{array}{l}.6571 E-05 \\
.2381 E-U 4 \\
.4757 E-04 \\
.1455 E-63 \\
.3831 E-63 \\
.5967 E-03 \\
.7837 E-03\end{array}$ \\
\hline $\begin{array}{l}.5000 E \\
.5200 E \\
.5400 E \\
.5500 E\end{array}$ & $\begin{array}{l}01 \\
01 \\
01 \\
01\end{array}$ & $\begin{array}{l}.3357 E-02 \\
.6105 E-02 \\
.8593 E-02\end{array}$ & $\begin{array}{l}.1060 E-02 \\
.3459 E-92 \\
.4750 E-02\end{array}$ \\
\hline $\begin{array}{l}.5750 E \\
.6000 E \\
.6500 E \\
.7000 \mathrm{E} \\
.7500 \mathrm{E} \\
.6500 \mathrm{E} \\
.9000 \mathrm{E} \\
.9500 \mathrm{E} \\
.100 \mathrm{CE}\end{array}$ & $\begin{array}{l}01 \\
01 \\
01 \\
01 \\
01 \\
01 \\
01 \\
01 \\
02\end{array}$ & $\begin{array}{l}.1443 E-01 \\
.1990 E-01 \\
.2574 E-01 \\
.2991 E-01 \\
.3579 E-01 \\
.4750 E-01 \\
.5407 E-01 \\
.5903 E-01 \\
.6417 E-01\end{array}$ & $\begin{array}{l}.6512 E-02 \\
.13 .5 E-01 \\
.2149 E-01 \\
.2782 E-11 \\
.3500 E-01 \\
.4750 E-01 \\
.5364 E-01 \\
.5856 E-01 \\
.6250 E-01\end{array}$ \\
\hline
\end{tabular}


Table VIII

Cross sections for the ${ }^{58} \mathrm{Ni}(n, p){ }^{58} \mathrm{Co}$

Reaction Based on an Eyegulde to Fxperisental

Data and EXDF/B-IV Fission Cross Sections

\section{A. 235 Y Monitor}

\begin{tabular}{|c|c|c|c|c|c|c|c|}
\hline $\begin{array}{c}E_{n} \\
(\mathrm{MeV})\end{array}$ & & $\left(\sigma_{n p} / \sigma_{F, 235}\right)$ & $\begin{array}{c}\sigma_{n p} \\
\text { (barn) }\end{array}$ & $\begin{array}{c}\mathbf{E}_{\mathbf{n}} \\
(\mathrm{MeV})\end{array}$ & & $\left(\sigma_{n p} / \sigma_{F}, 23.5\right.$ & $\begin{array}{c}\sigma_{\text {np }} \\
\text { (barn) }\end{array}$ \\
\hline $\begin{array}{l}. \$ 700 E \\
.5200 E \\
.6800 E \\
.7000 E \\
.7400 E \\
.1000 L \\
.8600 E \\
.9000 E \\
.1000 E \\
.1100 E \\
.1160 E \\
.1300 E \\
.1400 E\end{array}$ & $\begin{array}{l}00 \\
00 \\
00 \\
00 \\
00 \\
00 \\
00 \\
001 \\
01 \\
01 \\
01 \\
01 \\
01\end{array}$ & 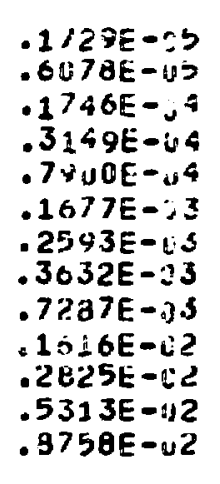 & 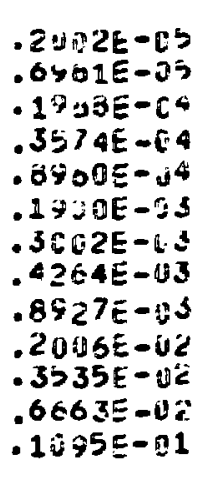 & $\begin{array}{l}.1500 E \\
.1006 E \\
.1700 E \\
.1200 E \\
.2600 E \\
.2200 E \\
.240 J E \\
.2500 E \\
.2650 E \\
.2850 E \\
.3000 E \\
.3250 E \\
.3500 E \\
.3750 E\end{array}$ & $\begin{array}{l}01 \\
41 \\
01 \\
01 \\
01 \\
01 \\
01 \\
01 \\
01 \\
01 \\
01 \\
01 \\
01 \\
01\end{array}$ & 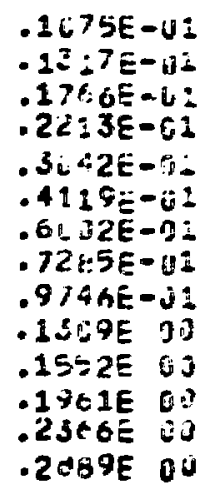 & 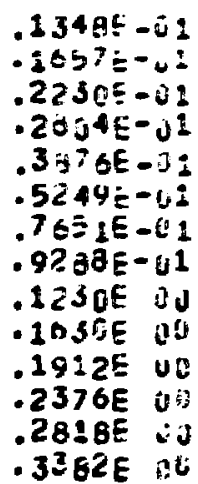 \\
\hline
\end{tabular}

B. ${ }^{238} \mathrm{U}$ Monttor

\begin{tabular}{|c|c|c|c|c|c|}
\hline$\underset{(\mathbf{H e V})}{\mathbf{E}_{\mathbf{n}}}$ & & $\left(\sigma_{\mathrm{np}} / \sigma_{\mathrm{F}, 2}\right.$ & $38^{\prime}$ & $\underset{\text { (barn }}{\sigma_{\text {np }}}$ & \\
\hline $\begin{array}{l}.4000 E \\
.4250 E \\
.4500 E \\
.4750 E \\
.5000 E \\
.5500 E \\
.5750 E \\
.5000 E \\
.7000 E \\
.3000 E \\
.9000 E \\
.1000 E\end{array}$ & $\begin{array}{l}01 \\
01 \\
i 11 \\
01 \\
i 1 \\
i 1 \\
01 \\
i 1 \\
01 \\
01 \\
01 \\
i 2\end{array}$ & $\begin{array}{l}.6631 E \\
.72 .32 E \\
.7680 E \\
.7877 E \\
.8261 E \\
.9205 E \\
.9304 E \\
.9101 E \\
.6090 E \\
.5865 E \\
.5720 E \\
.5749 E\end{array}$ & $\begin{array}{l}100 \\
00 \\
00 \\
00 \\
00 \\
00 \\
00 \\
00 \\
00 \\
00 \\
00 \\
00\end{array}$ & $\begin{array}{l}.3753 E \\
.4082 \mathrm{E} \\
.4324 E \\
.44 \mathrm{J3E} \\
.4535 \mathrm{E} \\
.5255 \mathrm{E} \\
.5553 \mathrm{E} \\
.5989 \mathrm{E} \\
.5664 E \\
.5306 \mathrm{E} \\
.5704 E \\
.5600 \mathrm{E}\end{array}$ & $\begin{array}{l}00 \\
00 \\
00 \\
06 \\
00 \\
00 \\
00 \\
00 \\
00 \\
00 \\
00 \\
60\end{array}$ \\
\hline
\end{tabular}


Table IX

Crose Sections for the ${ }^{59} \operatorname{Co}(n, p){ }^{59}$ Fe Reaction

Based on an Eyeguide to Experimental Data and EDF/B-IV Fission Cross Sections for ${ }^{238_{U}}$

\begin{tabular}{|c|c|c|c|}
\hline$\underset{(H e V)}{E_{n}}$ & & $\left(o_{n p}\left(\sigma_{F} .238\right)\right.$ & $\stackrel{a_{n p}}{\text { (barn) }}$ \\
\hline $\begin{array}{l}.4300 E \\
.5000 E \\
.5500 E \\
.8000 E \\
.6500 E \\
.7000 E \\
.7500 E \\
.8000 E \\
.8500 E \\
.9000 E \\
.9500 E \\
.1300 E\end{array}$ & $\begin{array}{l}01 \\
01 \\
0_{2} \\
01 \\
01 \\
01 \\
01 \\
01 \\
01 \\
01 \\
01 \\
02\end{array}$ & $\begin{array}{l}.2105 E-01 \\
.1765 E-01 \\
.2107 E-01 \\
.2314 E-01 \\
.2162 E-01 \\
.2062 E-01 \\
.2219 E-01 \\
.2447 E-01 \\
.2670 E-01 \\
.2735 E-01 \\
.3216 E-01 \\
.3591 E-01\end{array}$ & $\begin{array}{l}.6234 E-02 \\
.9796 E-02 \\
.1193 E-01 \\
.1530 E-02 \\
.1805 E-01 \\
.1910 E-01 \\
.2170 E-02 \\
.2423 E-01 \\
.2670 E-01 \\
.2912 E-01 \\
.3150 E-01 \\
.3410 E-01\end{array}$ \\
\hline
\end{tabular}



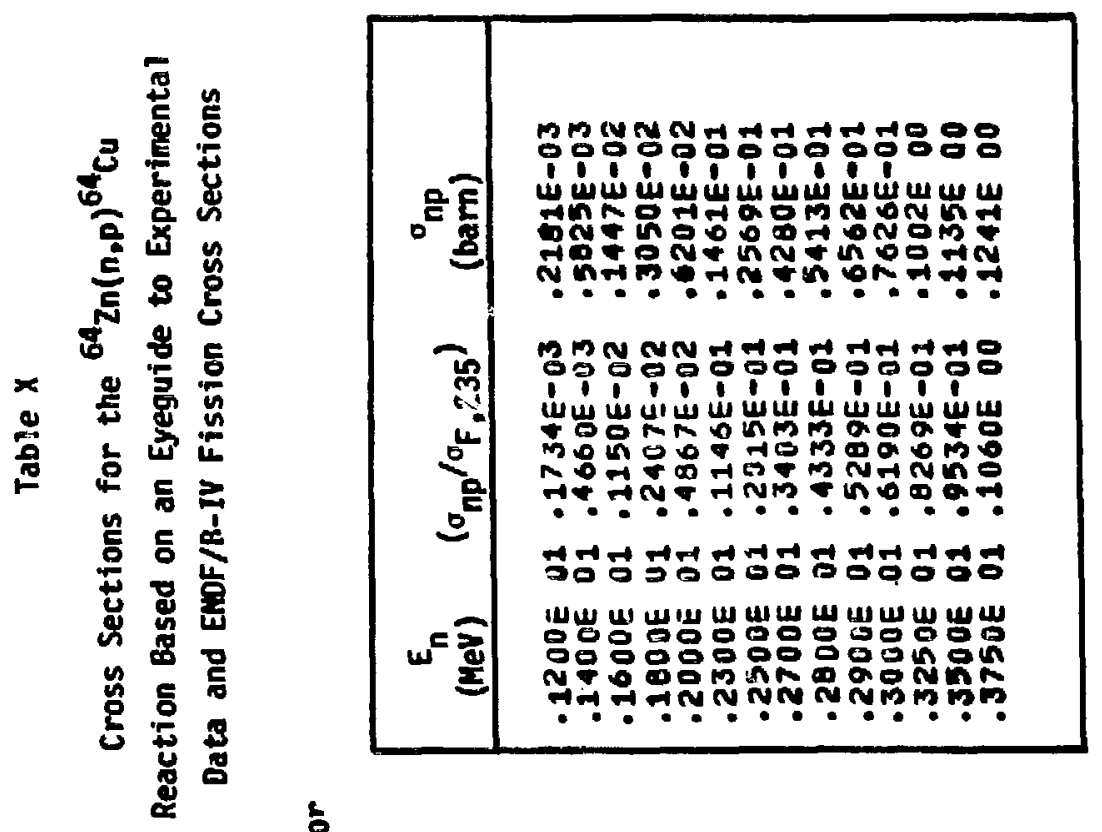

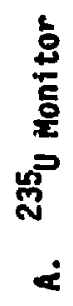

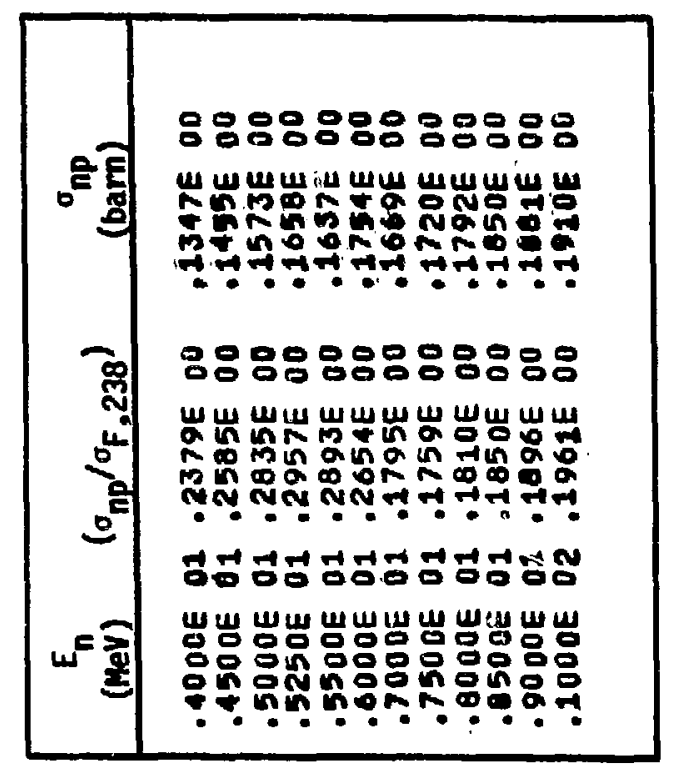

章

$\infty$ 
Table XI

Cross Sections for ${ }^{238} v(n, f)$ Reaction

Based on an Eyeguide to Experimental Data and

EMDF/B-IV Fission Cross Sections for ${ }^{235} u^{2}$

\begin{tabular}{|c|c|c|c|c|c|c|}
\hline $\begin{array}{c}E_{n} \\
(M e V)\end{array}$ & & $\begin{array}{c}\sigma_{f}, 238 \\
\text { (barn) }\end{array}$ & $\begin{array}{c}E_{n} \\
(M e V)\end{array}$ & & $\begin{array}{r}\sigma_{f, 238} \\
\text { (barn) }\end{array}$ & \\
\hline 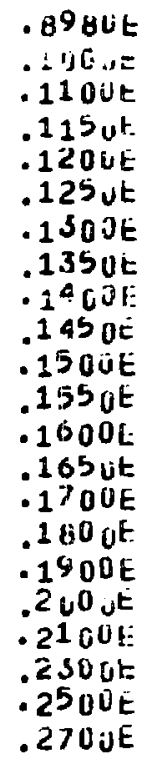 & 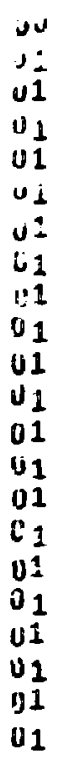 & 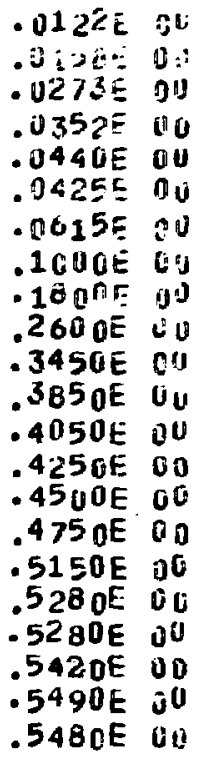 & $\begin{array}{l}.2900 E \\
.3106 E \\
.3300 E \\
.3500 E \\
.3700 E \\
.4500 E \\
.5000 E \\
.5200 E \\
.5400 E \\
.5600 E \\
.6000 E \\
.6200 E \\
.6400 E \\
.6800 E \\
.7200 E \\
.7400 E \\
.7600 E \\
.8000 E \\
.8500 E \\
.9000 E \\
.9500 E \\
.1000 E\end{array}$ & $\begin{array}{l}01 \\
01 \\
01 \\
01 \\
01 \\
01 \\
01 \\
01 \\
01 \\
01 \\
01 \\
01 \\
01 \\
01 \\
01 \\
01 \\
01 \\
01 \\
01 \\
01 \\
01 \\
01 \\
01 \\
02\end{array}$ & $\begin{array}{l}.5400 E \\
.5330 E \\
.3300 E \\
.5400 E \\
.5530 E \\
.5000 E \\
.5550 E \\
.3560 E \\
.5600 E \\
.5770 E \\
.6010 E \\
.7340 E \\
.8240 E \\
.8860 E \\
.9650 E \\
.9920 E \\
.1610 E \\
.1031 E \\
.1648 E \\
.1060 E \\
.1073 E \\
.1048 E\end{array}$ & $\begin{array}{l}00 \\
00 \\
00 \\
00 \\
00 \\
00 \\
00 \\
00 \\
00 \\
00 \\
00 \\
00 \\
00 \\
00 \\
00 \\
00 \\
01 \\
01 \\
61 \\
01 \\
01 \\
01\end{array}$ \\
\hline
\end{tabular}

a

${ }^{238} \mathrm{U} /{ }^{235_{U}}$ fission ratio data from J.W. Meadows [3] were utilized in the preparation of this table. 
Sumary of Response Calculation Results

\begin{tabular}{|c|c|c|c|c|}
\hline \multirow[b]{2}{*}{ Reaction "1" } & \multirow{2}{*}{$\underset{(\mathrm{MeV})}{E_{\mathrm{min}}}$} & \multirow{2}{*}{$\underset{\max }{E_{\max }}$} & \multicolumn{2}{|c|}{$\bar{\sigma}_{f}\left(E_{a v}, E_{m i n}, E_{\max }\right), a b^{a}$} \\
\hline & & & $E_{a v}=1.97 \mathrm{seV}$ & $E_{a v}=2.13 \mathrm{MeV}$ \\
\hline${ }^{27} \mathrm{Al}(\mathrm{n}, \mathrm{p})^{27} \mathrm{Mg}_{\mathrm{Bg}}$ & 2.8 & 10.0 & 3.72 & 4.64 \\
\hline${ }^{46} \mathrm{~T} 1(\mathrm{n}, \mathrm{p})^{46} \mathrm{Sc}$ & 3.6 & 10.0 & $(10.0)$ & (12.6) \\
\hline${ }^{47} \mathrm{~T} 1(\mathrm{n}, \mathrm{p})^{47} \mathrm{Sc}$ & 0.914 & 10.0 & 21.0 & 23.64 \\
\hline${ }^{48} \mathrm{TI}(\mathrm{n}, \mathrm{p})^{48} \mathrm{Sc}$ & 4.7 & 10.0 & $(0.227)$ & $(0.315)$ \\
\hline${ }^{54} \mathrm{Fe}(\mathrm{n}, \mathrm{p})^{54} \mathrm{Mn}$ & 2.0 & 10.0 & 74.3 & 86.1 \\
\hline${ }^{56} \mathrm{Fe}(\mathrm{n}, \mathrm{p}){ }^{56} \mathrm{Mn}$ & 4.0 & 10.0 & $(0.913)$ & (1.23) \\
\hline${ }^{58_{\mathrm{N} 1}(\mathrm{n}, \mathrm{p})}{ }^{58} \mathrm{Co}$ & 0.57 & 10.0 & 99.4 & 114 \\
\hline${ }^{59} \mathrm{Co}(\mathrm{n}, \mathrm{p}){ }^{59} \mathrm{Fe}$ & 4.3 & 10.0 & (1.11) & $(1.42)$ \\
\hline${ }^{64} \mathrm{Zn}(\mathrm{n}, \mathrm{p}){ }^{64} \mathrm{cu}$ & 1.2 & 10.0 & 32.8 & 37.5 \\
\hline${ }^{238} v(n, f)$ & 0.898 & 10.0 & 293 & 314 \\
\hline
\end{tabular}

${ }^{a} \sigma_{j}\left(E_{a v}, E_{m i n}, E_{\max }\right)$ computed using Eq. (4). $E_{a v}=1.97$ HeV corresponds to the neutron field for pure thermal fission of $235_{\mathrm{U}}$ while $\mathrm{E}_{\mathrm{av}}=2.13 \mathrm{MeV}$ corresponds to the spontaneous fission neutron field for ${ }^{252} \mathrm{c} f$ [11]. Valves expressed as (...) correspond to instances witere our experimental data fall to cover a significant portion of the response range (see Figs. 1-10). 
Table XIII

Comparison of Response Calculation Results

for ${ }^{235} \mathrm{U}$ Thermal Fission Neucrons with

Sone Corresponding Values from the Literature

\begin{tabular}{|c|c|c|c|c|}
\hline \multirow[b]{2}{*}{ Reaction "f" } & \multirow{2}{*}{$\begin{array}{c}\bar{v}_{f}, \mathrm{mb} \\
\text { Present } \\
\text { Work }\end{array}$} & \multicolumn{3}{|l|}{$\bar{\sigma}_{\mathrm{f}}\left(\mathrm{x}_{25, \mathrm{f}}\right), \mathrm{ab}$} \\
\hline & & $\begin{array}{l}\text { Simons and } \\
\text { HcElroy }(1970)^{b}\end{array}$ & $\begin{array}{l}\text { Fabry } \\
(1972)\end{array}$ & $\begin{array}{l}\text { ENDE/B-TV } \\
(1975)^{d}\end{array}$ \\
\hline${ }^{27}{ }_{A 2(n, p)}{ }^{27} \mathrm{Mg}_{\mathrm{g}}$ & 3.72 & - & $4.0 \pm 0.4$ & 4.222 \\
\hline${ }^{46} T 1(n, p){ }^{46} S c$ & $(\mathbf{1 0 . 0 )}$ & 11.3 & $12.3 \pm 0.5$ & 10.24 \\
\hline${ }^{47} \mathrm{TI}(\mathrm{n}, \mathrm{p})^{47} \mathrm{Sc}$ & 21.0 & 17.2 & $20 \pm 2$ & 21.4 \\
\hline${ }^{48} T i(n, p){ }^{48} T I$ & $(0.227)$ & 0.236 & $0.315 \pm 0.02$ & 0.194 \\
\hline${ }^{54} \mathrm{Fe}(\mathrm{n}, \mathrm{p})^{54} \mathrm{Mn}$ & 74.3 & 76.3 & $82.5 \pm 2$ & 77.67 \\
\hline$\left.{ }^{56_{F e}(n, p)}\right)^{56_{M n}}$ & $(0.913)$ & - & $1.07 \pm 0.06$ & 1.145 \\
\hline${ }^{58}{ }_{\mathrm{N} 1(\mathrm{n}, \mathrm{p})}{ }^{58} \mathrm{Co}$ & 99.4 & 102.0 & $113 \pm 2.5$ & 101.5 \\
\hline${ }^{59} \mathrm{Co}(\mathrm{n}, \mathrm{p}){ }^{59} \mathrm{Fe}$ & (1.11) & - & - & - \\
\hline${ }^{64} \mathrm{Zn}(\mathrm{n}, \mathrm{p}){ }^{64} \mathrm{Cu}$ & 32.8 & - & $31 \pm 1.5$ & - \\
\hline${ }^{238} \mathrm{u}(\mathrm{n}, \mathrm{f})$ & 293 & 287.0 & $328 \pm 10$ & 295.4 \\
\hline
\end{tabular}

a see rble XII.

b Ref. y. Calculated using the Watt spectrum [12] and SAND-II Evaluated Reference Cross Section Library (1970 version).

C Ref. 10. Evaluated Integral cross sections.

d Refs, 5 and 13 .

Computed using Eq. (1) with $\mathrm{E}_{\text {av }}=1.98 \mathrm{MeV}$ and ENDF/B-IV monoenergetic $(n, p)$ and ${ }^{238} \mathrm{U}$ fission cross sections. 
Table XIV

Hass Analysis of ${ }^{235} \mathrm{v}$ Depos it Materfal

\begin{tabular}{|c|c|c|c|}
\hline Isotope & Abundance & $\begin{array}{l}\text { Decay } t_{1 / 2} \\
\text { (Years) }\end{array}$ & $\begin{array}{l}\text { Contribution to } \\
\text { Spectfic Activity } \\
\text { (d/sec/Hg) }\end{array}$ \\
\hline $234_{y}$ & 0.856 & $(2.455 \pm 0.017) \times 10^{5} \mathrm{a}$ & $1.961 \pm 0.014$ \\
\hline $235 \mathrm{v}$ & 93.249 & $(7.0381 \pm 0.0048) \times 10^{8} b$ & 0.074 \\
\hline${ }^{236} \mathrm{v}$ & 0.332 & $(2.3415 \pm 0.0014) \times 10^{7} \mathrm{c}$ & 0.008 \\
\hline $238 v$ & 5.526 & $(4.4683 \pm 0.0034) \times 10^{9} \mathrm{c}$ & $5 \times 10^{-6}$ \\
\hline
\end{tabular}

Total Specific Activity for ${ }^{235} \mathrm{y}$ Deposit Material:

Measured $=2.065 \pm 0.011 \mathrm{~d} / \mathrm{sec} / \mathrm{\mu B}_{\mathrm{B}}$

Calculated $=2.043 \pm 0.014 \mathrm{~d} / \mathrm{sec} / \mu \mathrm{g}$
a Ref. 14.
b Ref. 15.
c Ref. 16. 
Figs. 1 thru 10. Response of the $(n, p)$ reactions for $27_{A \ell,} 46,47,48_{T 1}, 54,56_{F e}$ ${ }^{58} \mathrm{N1},{ }^{59} \mathrm{Co}$ and ${ }^{64} \mathrm{Zn}$, and of f1ssion of ${ }^{238} \mathrm{v}$ in reference neutron fields corresponding to 1) thermal-neutron fission of ${ }^{235} \mathrm{v}$ and 11) spontaneous fisston of ${ }^{252} \mathrm{cf}$. Symbols: ( $t$ ) Points selected from eyeguide, $\sigma(E)$, to the experimental cross section data. Dashed line shows the reference neutron spectrum, $X(E)$. Solld line show the response function, $R(E)=$ $X(E) \cdot \sigma(E)$. Plots are arbitrarily normalized to place maximn for each curve at the top border of frame.

ANL Negative Numbers

Fig. 1 (116-2749)

Fig. $2(116-2745)$

Fig. $3(116-2746)$

Fig. $4(116-2753)$

Sig. $5(116-2750)$

Fig. 6 (116-2752)

Fì. 7 (116-2751)

Fig. 8 (116-2748)

Fig. $9(116-2747)$

Fig. 10 (116-2754) 
Fig. 1
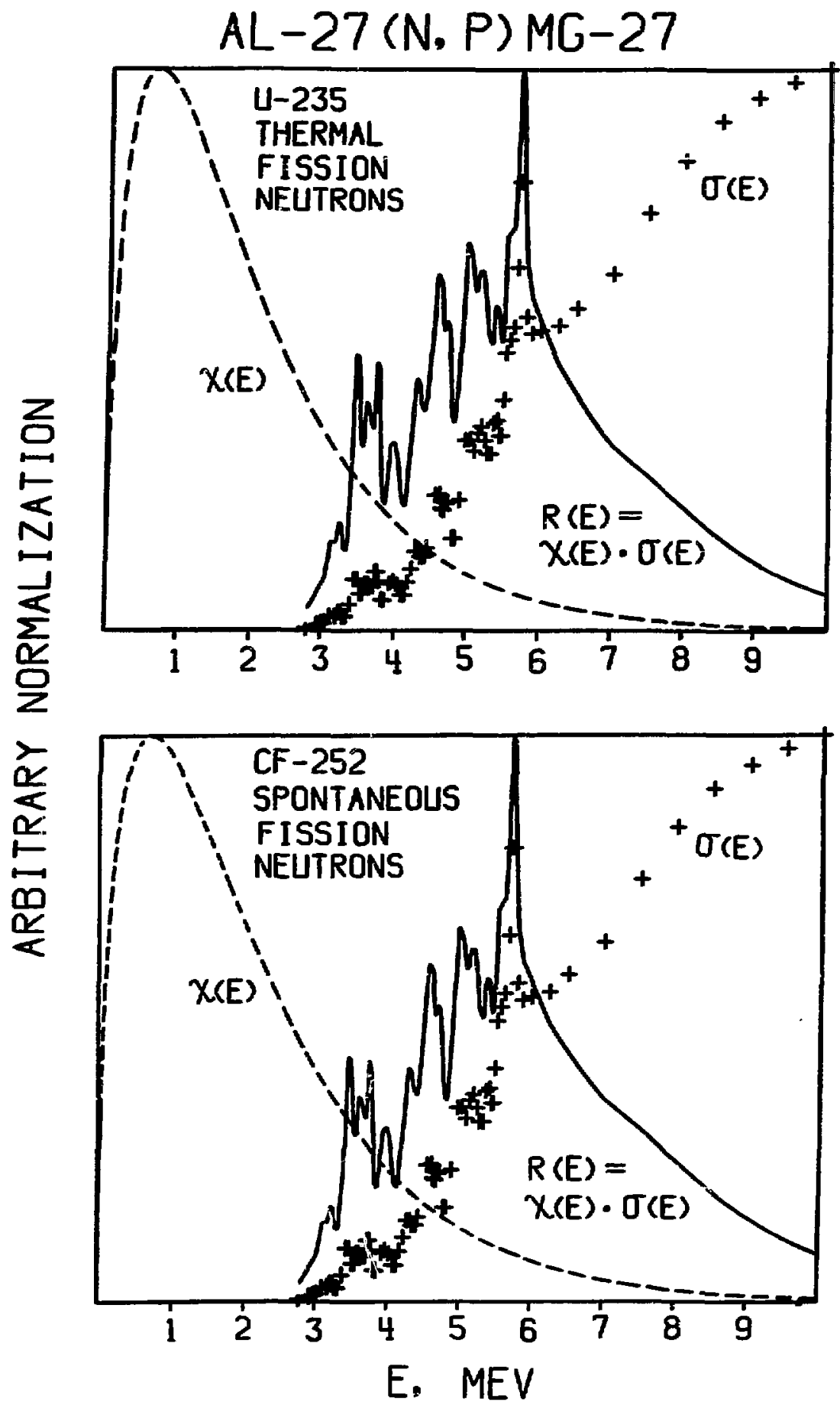
Fig. 2

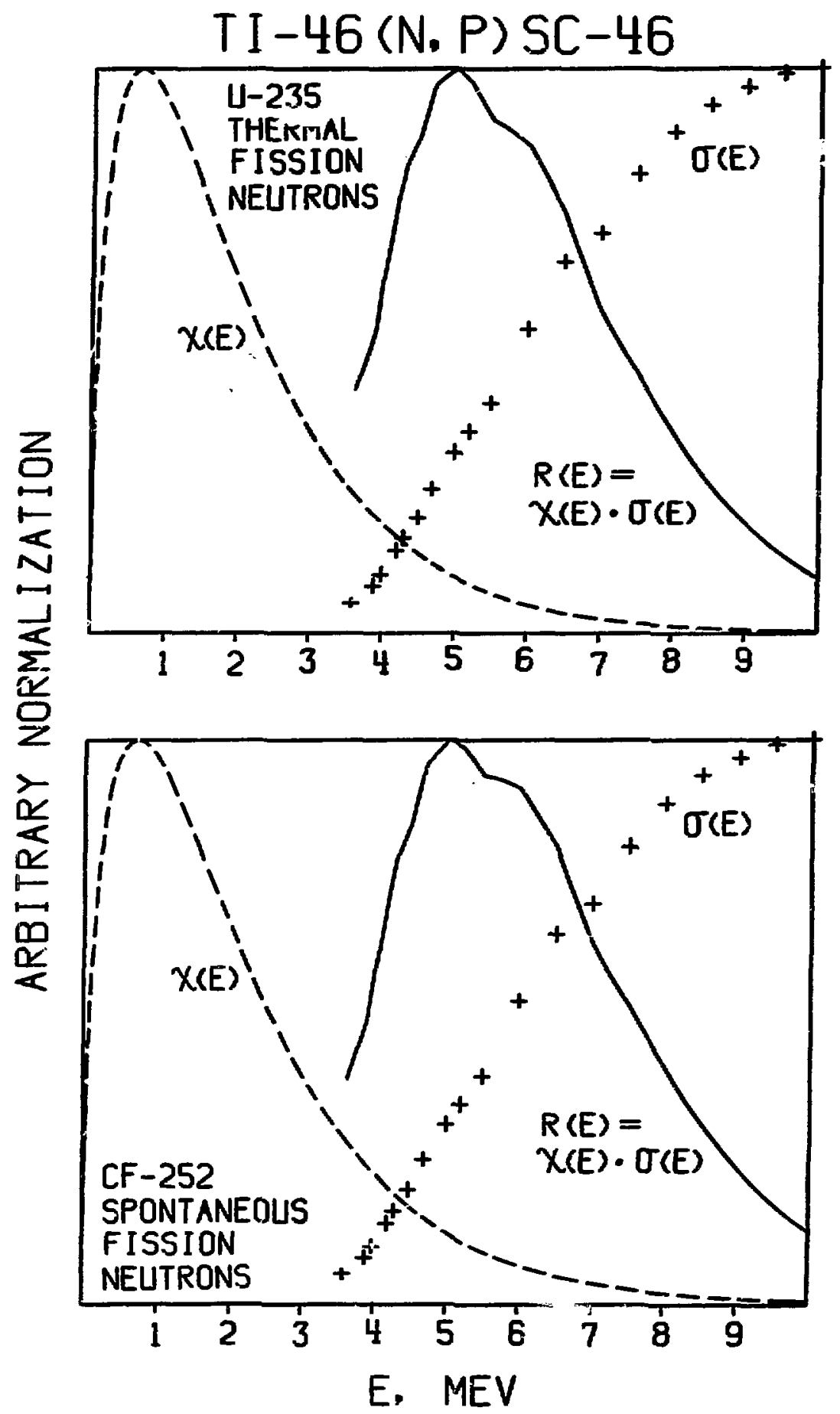


Fig. 3

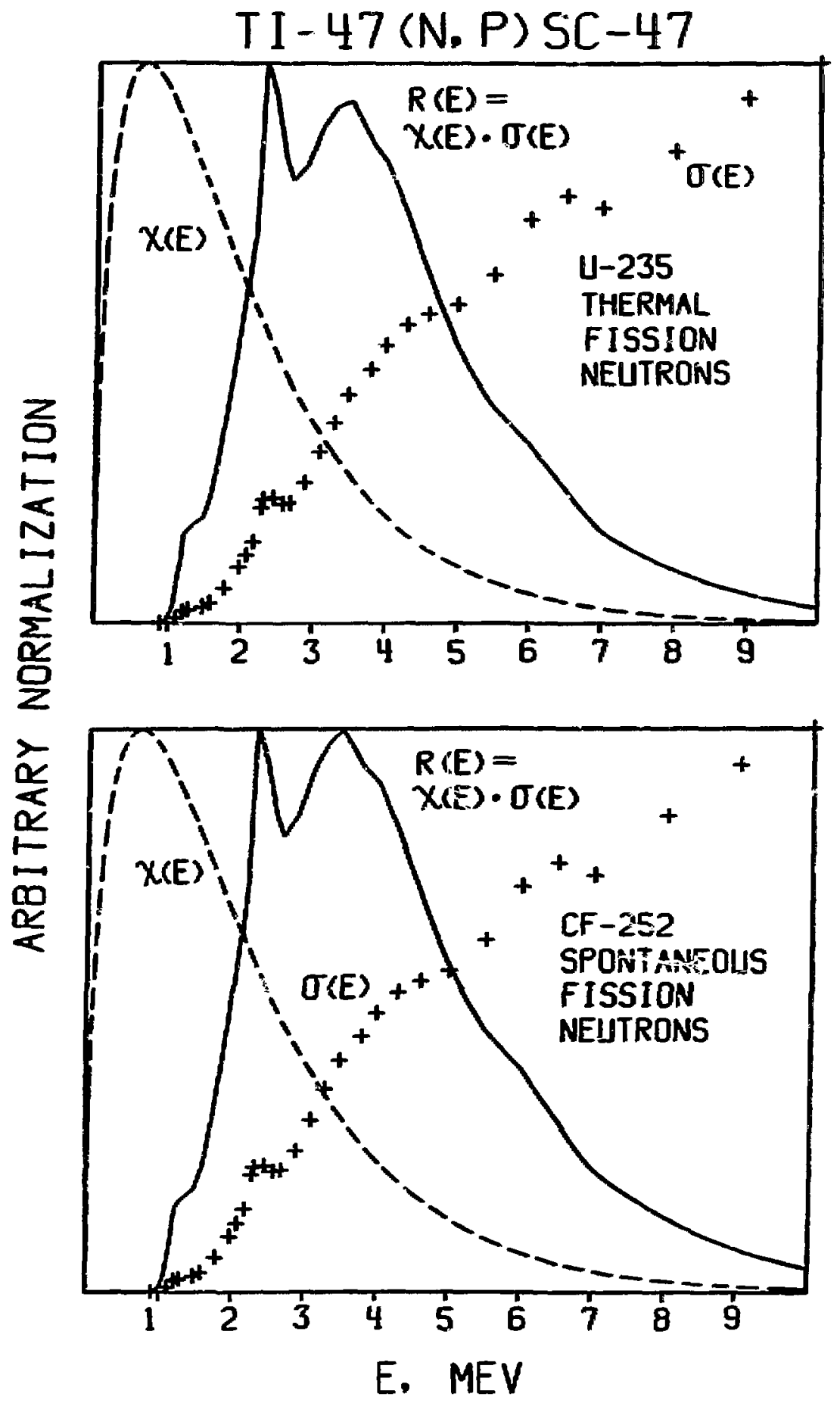


Fig. 4

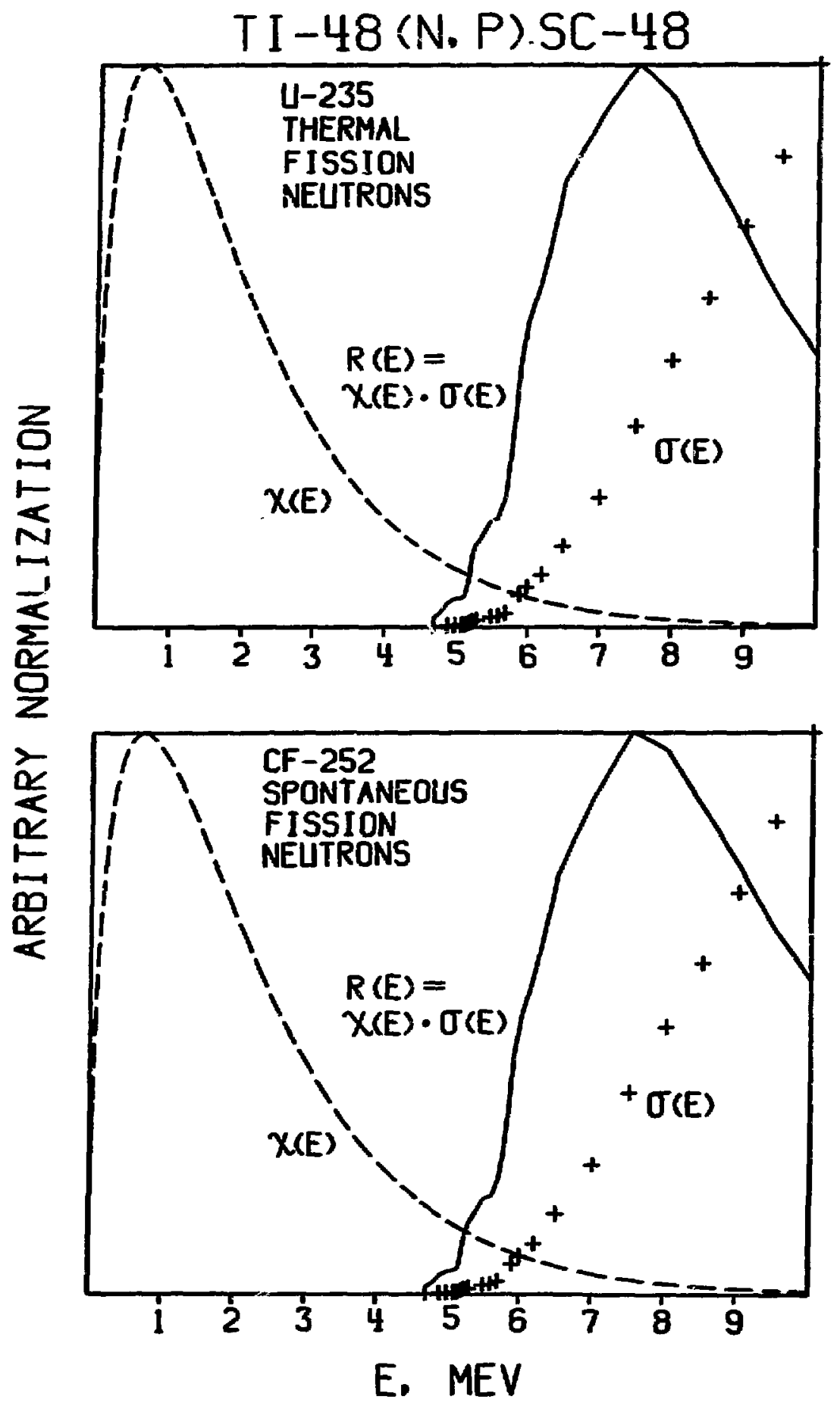


Fig. 5

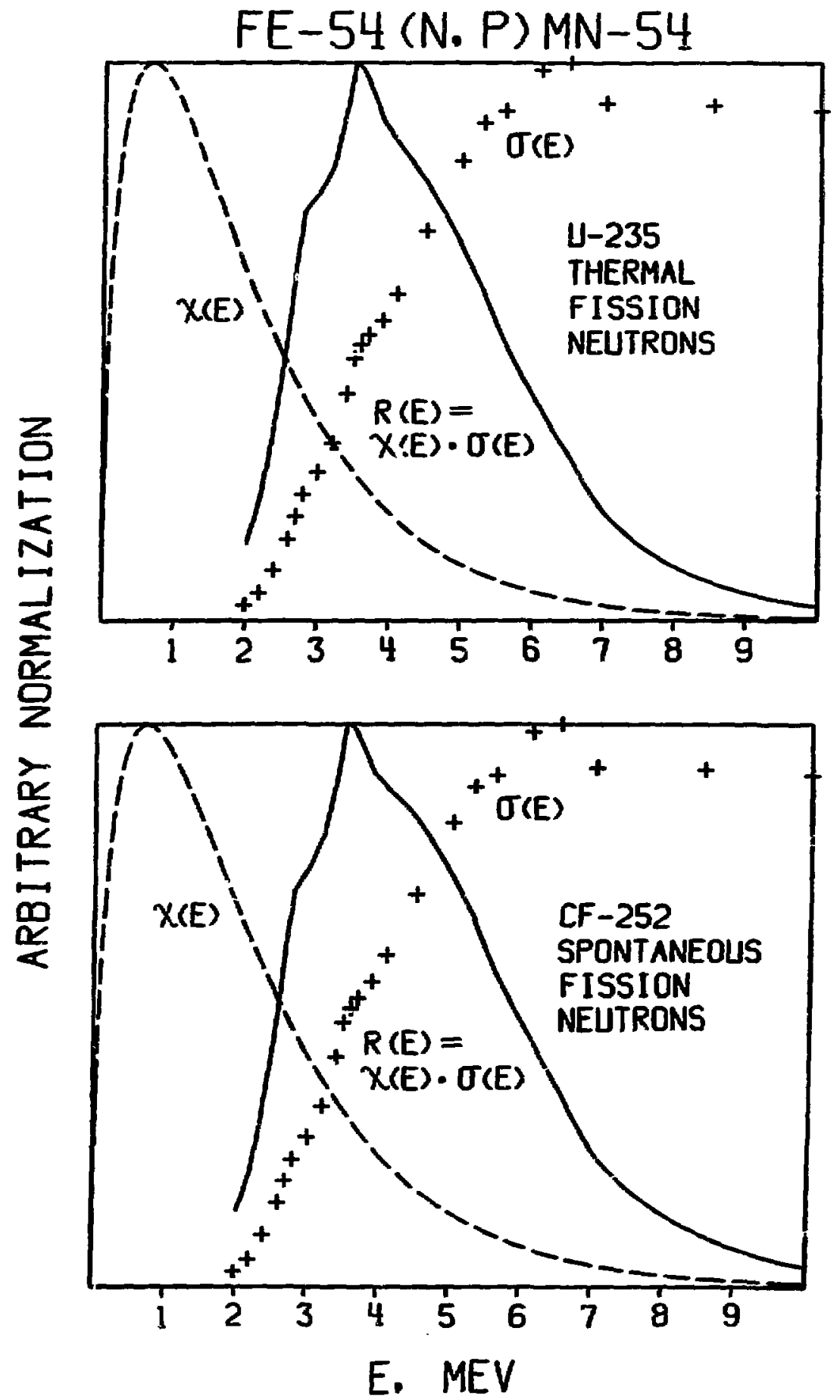


Fig. 6

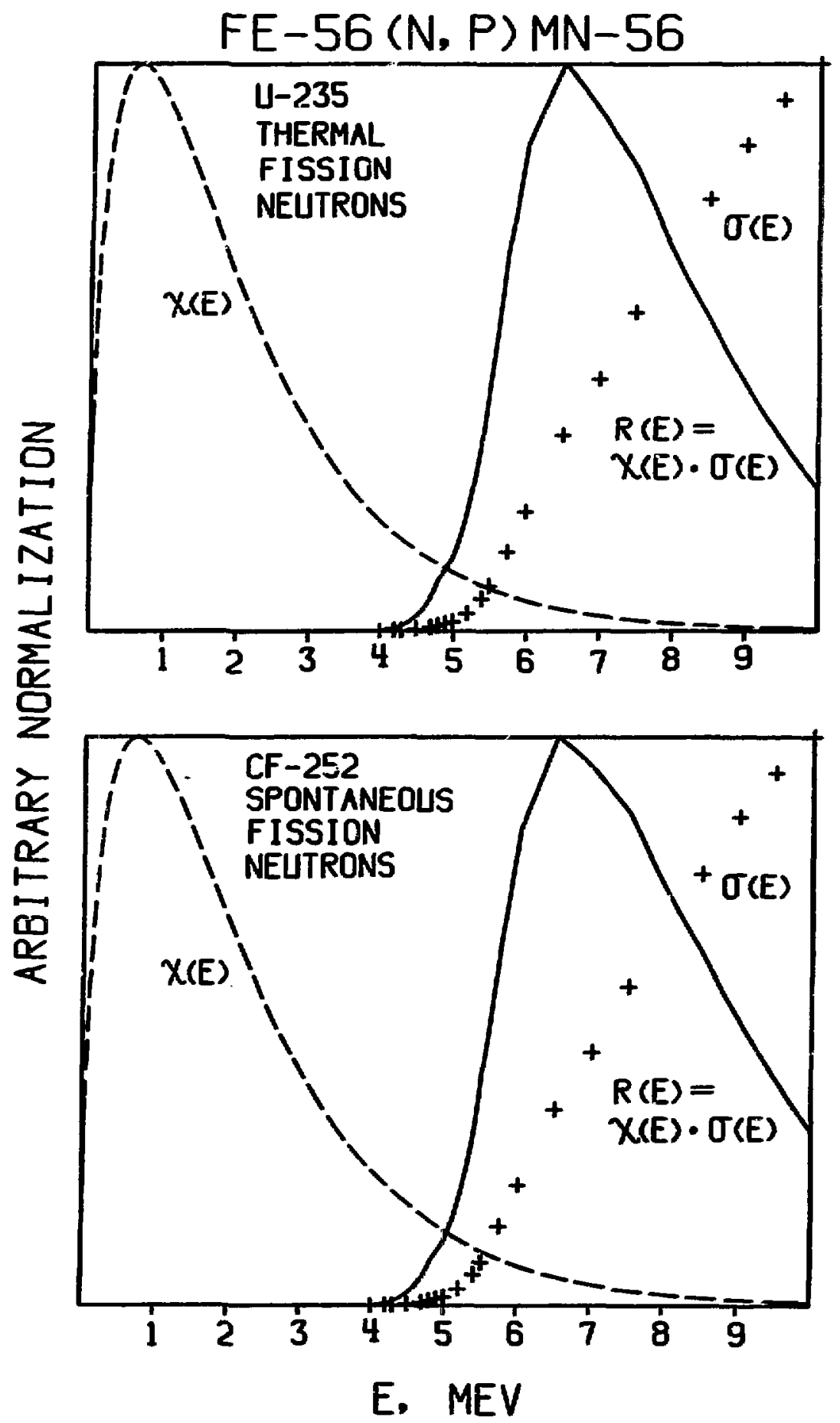


Fig. 7

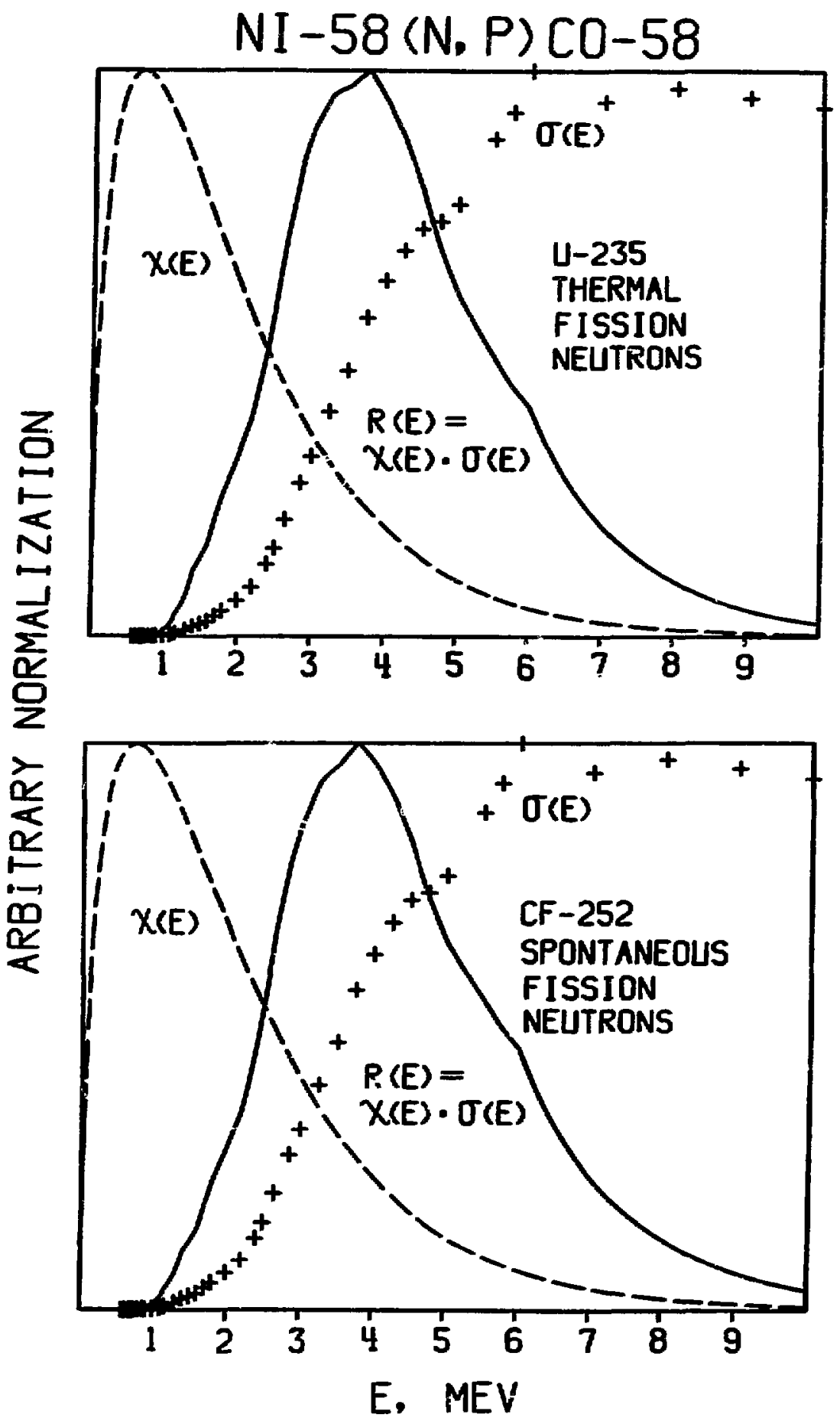



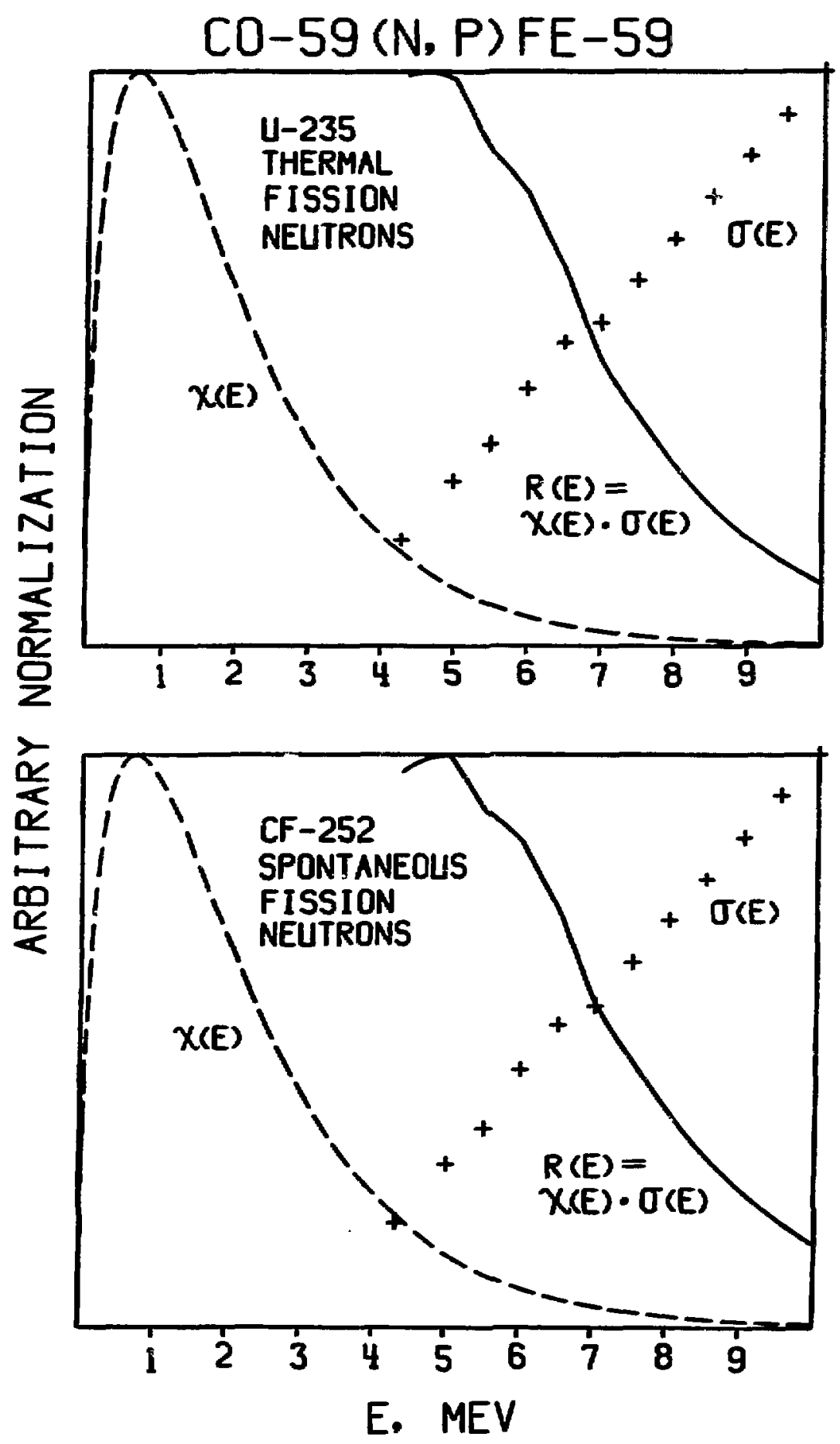
Fig. 9

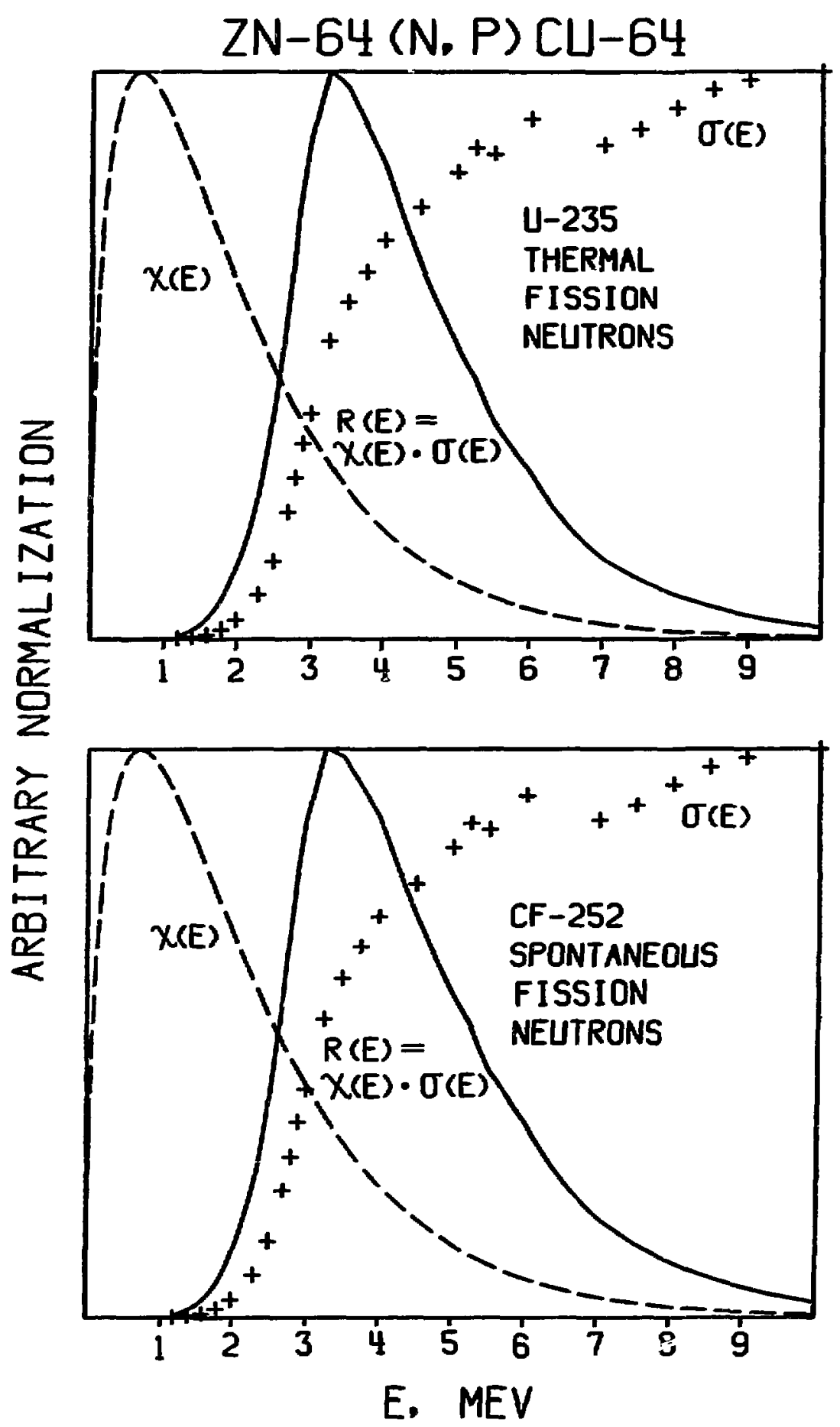



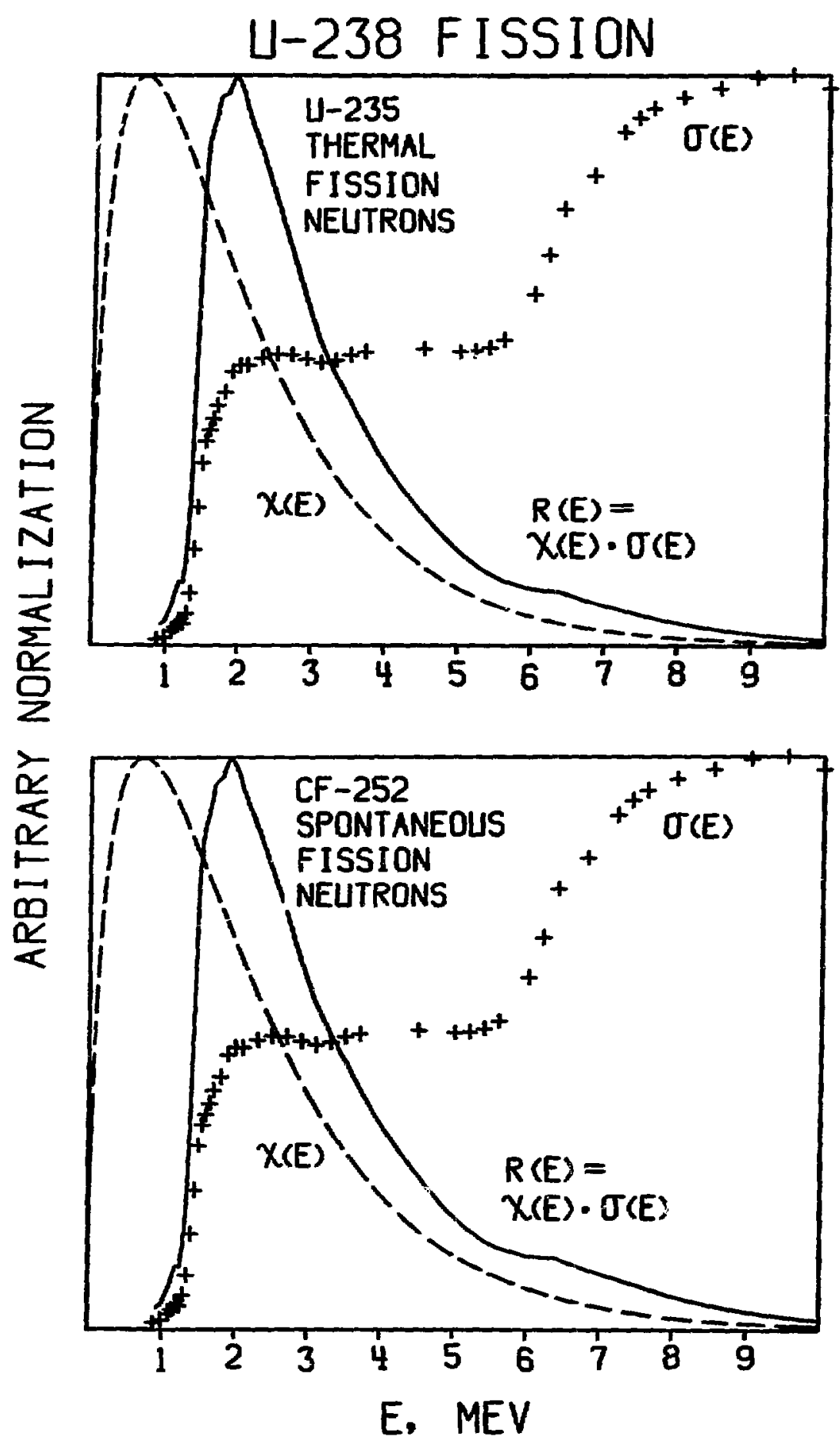